\title{
马来酰亚胺双键参与的官能化反应研究进展
}

\author{
杨振华祝家楠文彩月葛迎香赵圣印* \\ (东华大学化学化工与生物工程学院 生态纺织教育部重点实验室 上海 201620)
}

\begin{abstract}
摘要 马来酰亚胺是一类海洋天然生物碱、生物活性分子和功能材料的重要结构母核, 并能转化为琥珀酰亚胺、四氢 吡咯及 2-吡咯酮等化合物, 具有广泛的应用价值. 以马来酰亚胺为合成子构建含有马来酰亚胺和琥珀酰亚胺结构单元 的化合物已成为有机合成研究热点之一. 对马来酰亚胺双键参与的官能化反应进行了综述, 重点在马来酰亚胺的 Michael 加成、氧化偶联和环加成反应.
\end{abstract}

关键词 马来酰亚胺; Michael 加成; 氧化偶联; 环加成反应

\section{Recent Advances in Functionalization of Double Bond Based on Maleimides}

\author{
Yang, Zhenhua Zhu, Jianan Wen, Caiyue Ge, Yingxiang Zhao, Shengyin* \\ (Key Laboratory of Science and Technology of Exo-Textile, Ministry of Education, College of Chemistry, Chemical \\ Engineering and Biotechnology, Donghua University, Shanghai 201620)
}

\begin{abstract}
Maleimide, a common motif in a variety of natural alkaloids, has been extensively investigated due to its noteworthy biological activities and optical properties. Additionally, it can be transformed into many important heterocyclic frameworks such as succinimides, pyrrolidines, and 2-pyrrolidones. Thus, a great deal of attention has been focused on the development of new synthetic routes to access polyfunctionalized maleimides. In this article, the recent research progress in functionalization of double bond is reviewed based on maleimides according to Michael addition, oxidative coupling and cycloaddition reaction.
\end{abstract}

Keywords maleimide; Michael addition; oxidative coupling; cycloaddition reaction

马来酰亚胺是一类海洋天然生物碱和生物活性分 子的重要结构母核, 例如海洋天然生物碱 Granulatimide (1)、Himanimide A (2)、Camphorataimide B (3)以及化合 物 4 等结构中含有马来酰亚胺的结构片段 ${ }^{[1 \sim 3]}$, 具有抗 肿瘤和抗菌等多种生物活性. 其中 Granulatimide (1)对 鼠 P388 白血病细胞的 $\mathrm{IC}_{50}$ 为 $39 \mu \mathrm{mol} / \mathrm{L}^{[1]}$, 化合物 Himanimide A (2) 对 LPS 诱导巨噬细胞因子 IL-6 抑制作 用的 $\mathrm{IC}_{50}$ 值达到 $10 \mu \mathrm{g} / \mathrm{mL}^{[2]}$. 化合物 4 为 2017 年 Poulsen 等 ${ }^{[3]}$ 报道的一种特异性 Porcupine(PORCN)抑制剂, 也可 以有效抑制 $\mathrm{Wnt}$ 信号通路, $\mathrm{IC}_{50}$ 为 $0.4 \mathrm{nmol} / \mathrm{L}$, 显示抗肿 瘤活性, 具有较好的研究价值和应用前景.

另外, 马来酰亚胺经化学转化还可以合成琥珀酰亚 胺、四氢吡咯和 2-吡咯酮等化合物, 如抗㾸㾋药苯琥胺
(Phensuximide, 5)、抗肿瘤药物米哚妥林(Midostaurin, 6) 和天然产物(Amathaspiramide $\mathrm{B}, 7$ ) 等 ${ }^{[4,5]}$ (图 1), 其中米 哚妥林为美国食品药品监督管理局(FDA)于 2017 年批 准上市的一种新型口服多靶点激酶抑制剂, 用于携带 FTL3 突变的急性髓性白血病(AML)患者的治疗 ${ }^{[4]}$.

鉴于马来酰亚胺和琥珀酰亚胺类化合物具有广泛 的应用价值, 研究简便有效、高选择性地构建含有马来 酰亚胺和琥珀酰亚胺结构单元的杂环化合物具有重要 的意义, 已经成为国内外有机合成化学的研究热点之

近年来, 有关马来酰亚胺类化合物的合成方法主要 包括以下两种: (1)马来酰亚胺或琥珀酰亚胺环的合成, 如将 2,3-二取代丁二酸化合物脱水制备丁二酸酐，随后

\footnotetext{
* Corresponding author. E-mail: syzhao8@dhu.edu.cn

Received February 14, 2019; revised April 10, 2019; published online April 19, 2019.

Project supported by the Shanghai Municipal Natural Science Foundation (No. 15ZR1401400) and the National Undergraduate Training Program for Innovation and Entrepreneurship in Donghua University (2018).

上海市自然科学基金(No. 15ZR1401400)和东华大学国家级大学生创新性实验(2018)资助项目.
} 


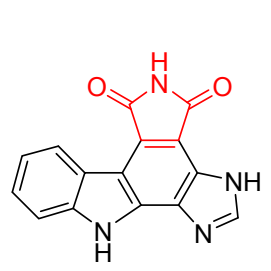

Granulatimide 1

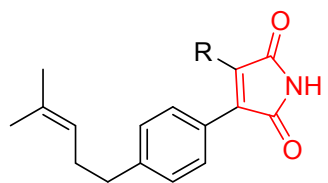

Himanimide $A(R=B n) 2$

Camphorataimide $B\left(R={ }^{i} \mathrm{Pr}\right) 3$ anti-inflammatory agents<smiles>O=C(CN1CCCC2=C1C(=O)NC2=O)Nc1ccc(-c2cccnc2)nn1</smiles>

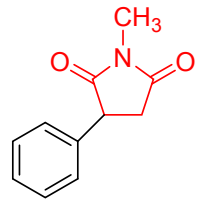

Phensuximide 5

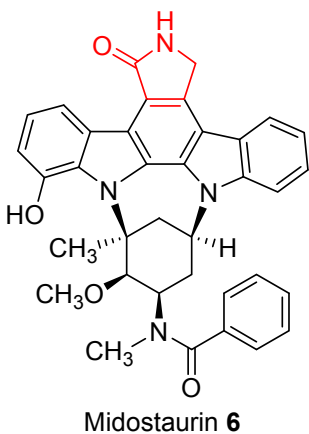

图 1 具有重要生物活性的天然产物或生物活性分子的化学 结构

Figure 1 Selected examples of biologically relevant maleimide derivatives

胺解制得琥珀酰亚胺类化合物, 最后氧化得到马来酰亚 胺 ${ }^{[6]}$; 也可以采用过渡金属催化炔、 $\mathrm{CO}$ 和胺类化合物环 合制备琥珀酰亚胺类化合物 ${ }^{[7]}$. (2)以马来酰亚胺及其衍 生物 3-溴马来酰亚胺等为合成子构建马来酰亚胺类化 合物, 特别是近年来马来酰亚胺及 $N$-取代的马来酰亚 胺的产业化, 为该类合成提供了廉价的原料. 其官能化 反应主要围绕马来酰亚胺的双键展开, 包括 Michael 加 成反应、氧化偶联反应和 Diels-Alder 反应等, 并通过对 马来酰亚胺分子结构中酰亚胺基团的还原, 也可以构建 含四氢吡咯类及 2-吡咯酮类化合物. 本文对马来酰亚胺 双键参与的 Michael 加成、氧化偶联反应和环加成反应 等进行综述，探讨其在有机合成领域中的应用.

\section{Michael 加成反应}

马来酰亚胺参与的 Michael 加成反应是合成琥珀酰 亚胺类化合物一种较为常用的方法. 近年来由于手性合 成技术的发展，不对称 Michael 加成反应也成为众多科 学家的研究热点之一. 马来酰亚胺的 Michael 加成反应 按照加成原子的不同, 可以分为马来酰亚胺与碳原子的
Michael 加成反应和马来酰亚胺与杂原子的 Michael 加 成反应.

\section{1 马来酰亚胺与碳原子的 Michael 加成反应}

马来酰亚胺与碳原子化合物发生 Michael 加成反应 是合成 3-取代琥珀酰亚胺类化合物的主要合成方法.

1.1.1 马来酰亚胺与吲哚等杂环化合物的 Michael 加 成反应

2005 年, Prudhomme 等 ${ }^{[8]}$ 报道了将取代吲哚和 $N$-取 代马来酰亚胺在醋酸中回流 $36 \mathrm{~h}$ 制备吲哚琥珀酰亚胺 类化合物，收率为 $25 \% \sim 74 \%$. 但该反应存在反应时间 较长，且在质子酸作用下，马来酰亚胺类化合物容易聚 合等缺点, 反应收率较低(Eq. 1).

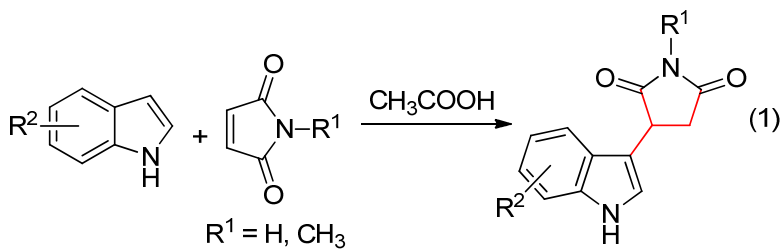

2013 年, 本课题组安玉龙等 ${ }^{[9]}$ 用 Lewis 酸 $\mathrm{ZnCl}_{2}$ 或 $\mathrm{AlCl}_{3}$ 作为催化剂, 实现了取代吲哚和吡咯对马来酰亚 胺类化合物的 Michael 加成反应. 与使用醋酸作催化剂 相比，该方法具有价格便宜、操作简便，而且对空气和 水很稳定、收率高等优点，是一种制备吲哚琥珀酰亚胺 类化合物的有效方法，收率为 $82 \% \sim 96 \%$ (Scheme 1).

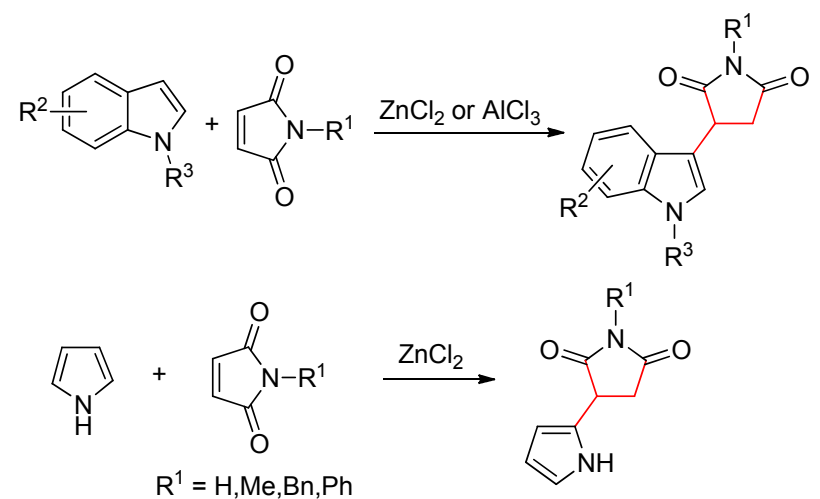

图式 1 Lewis 酸催化吲哚和吡咯与马来酰亚胺的 Michael 加 成

Scheme 1 Lewis acid catalyzed Michael addition of indoles and pyrroles to maleimides

通常, 在 Lewis 酸催化下, 吲哚 3-位的富电子的氢 会与马来酰亚胺发生加成反应. 2015 年, Prabhu 等 ${ }^{[10]}$ 成 功实现了吲哚-1-位苯甲酰基定位的吲哚-2-位与马来酰 亚胺的区域选择性 Michael 加成反应, 得到了吲哚-2-位 取代的琥珀酰亚胺类化合物，收率为 $44 \%$ 78\%，但是 该反应仅仅适用于 $\mathrm{N}$ 上取代的马来酰亚胺(Eq. 2). 


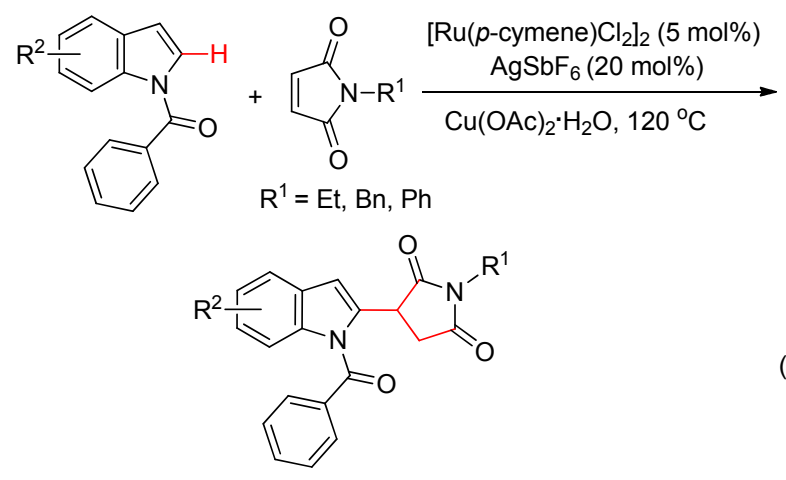

2017 年, Prabhu等 ${ }^{[11]}$ 又报道了采用吲哚-1-位 $N$ 原子 上嘧啶基团作为导向基, $N$-嘧啶取代的吲哚与马来酰亚 胺在钴催化剂的作用下在三氟乙醇中可以顺利实现吲 哚-2-位选择性 Michael 加成反应, 得到吲哚-2-取代的琥 珀酰亚胺类化合物, 收率为 30\% 98\% (Eq. 3).

$$
\text { ( }
$$

2017 年, $\mathrm{Li}$ 研究小组 ${ }^{[12]}$ 同样以 $\left[\mathrm{Cp} * \mathrm{Co}(\mathrm{CO}) \mathrm{I}_{2}\right]$ 作为 催化剂, $N$-(2-嘧啶基)吲哚和 $N$-取代基马来酰亚胺为反

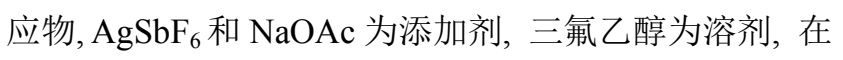
$30{ }^{\circ} \mathrm{C}$ 下反应得到了一系列带有琥珀酰亚胺结构的吲哚 类化合物, 收率为 $45 \% \sim 95 \%$ (Eq. 4).<smiles>[R]CNC</smiles>

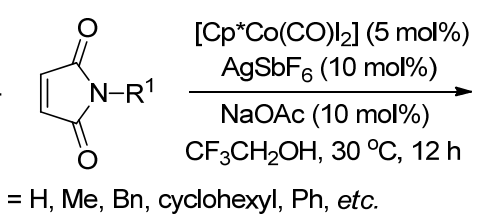<smiles>[R]N1C(=O)CC(c2cc3ccccc3n2-c2ncccn2)C1=O</smiles>

2017 年, Song 等 ${ }^{[13]}$ 报道了 $\mathrm{Mn}_{2}(\mathrm{CO})_{10}$ 催化的吲哚-2位与马来酰亚胺在乙酸乙酯中化学选择性 Michael 加成 反应. 该反应以 2-吡定基为定位基团, 无需任何添加剂 就可以得到 2-取代吲哚琥珀酰亚胺类化合物, 收率为 $46 \% \sim 96 \%$ (Eq. 5).

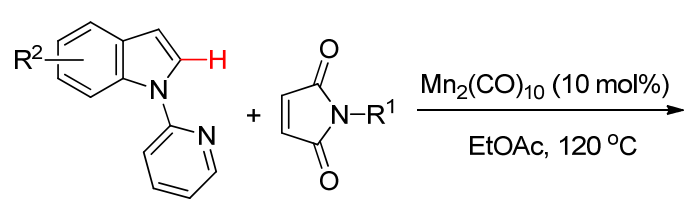

$\mathrm{R}^{1}=\mathrm{H}, \mathrm{Me}, \mathrm{Et}, t-\mathrm{Bu}, \mathrm{Bn}$, cyclohexyl, Ph, etc.<smiles>[R]N1C(=O)CC(c2cc(C#[R])cn2-c2ccccn2)C1=O</smiles>

2018 年, Prabhu 等 ${ }^{[14]}$ 报道了一种以 $\left[\mathrm{RhCp} * \mathrm{Cl}_{2}\right]_{2}$ 为 催化剂, 3 位三氟乙酰基为定位基实现吲哚-4-位的官能 团化反应. 研究表明, 铑催化的马来酰亚胺与吲哚的反 应在加入酸性添加剂醋酸时发生 1,4-加成反应，生成琥 珀酰亚胺类化合物, 收率为 $55 \% \sim 80 \%$; 当加入碱性添 加剂碳酸银时发生 Heck 型偶联反应, 生成马来酰亚胺 类化合物, 收率为 $50 \% \sim 76 \%$ (Scheme 2).

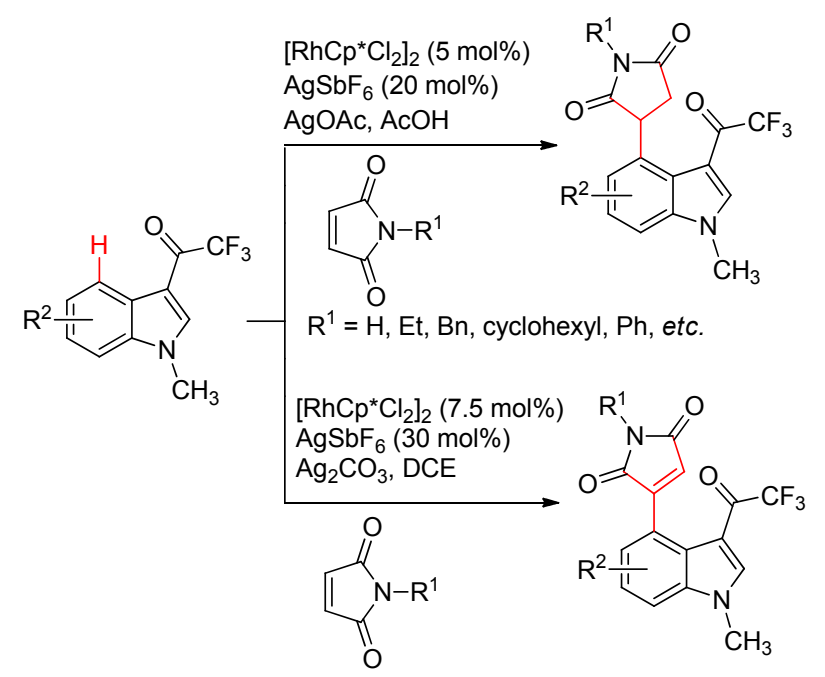

图式 2 吲哚 $\mathrm{C} 4$ 位 $\mathrm{C}-\mathrm{H}$ 官能团化

Scheme $2 \mathrm{C}-\mathrm{H}$ functionalization at the $\mathrm{C} 4$-position of indoles

2018 年, $\mathrm{Yu}$ 等 ${ }^{[15]}$ 报道了一种铑 $\left[\mathrm{RhCp}^{*} \mathrm{Cl}_{2}\right]_{2}$ 催化的 选择性吲哚 7 位官能团化反应. 该反应以吲哚-1-位的乙 酰基为定位基, 在铑催化下吲哚-7-位与马来酰亚胺发 生 Michael 加成得到吲哚-7-位取代的琥珀酰亚胺类化合 物, 收率为 $55 \% \sim 90 \%$ (Eq. 6).

\subsection{2马来酰亚胺与苯环的 Michael 加成反应}

马来酰亚胺双键亲电性较弱, 通常需要 Lewis 酸活 化. 2006 年 Koltunov 等 ${ }^{[16]}$ 报道了苯与马来酰亚胺发生 Michael 加成反应，该反应需要使用 $2 \sim 4$ equiv. 的 $\mathrm{AlCl}_{3}$, 反应底物适应性较差, 仅仅报道了 3 个反应实例, 以苯 甲醚为原料反应收率达到 $83 \%$, 但是以 3,4 -二氯苯和甲 苯为原料, 反应收率分别为 $34 \%$ 和 $66 \%$ (Eq. 7). 


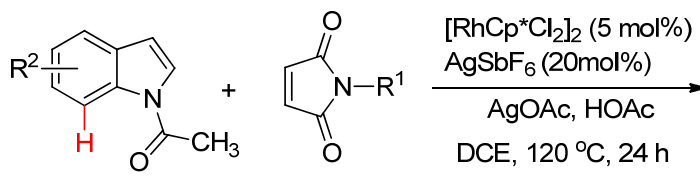

$\mathrm{R}^{1}=\mathrm{Me}, \mathrm{Et}, \mathrm{Bn}$, allyl, cyclohexyl, $\mathrm{COOCH}_{3}, \mathrm{Ph}$<smiles>[R][R]1ccc2ccn(C(C)=O)c2c1C1CC(=O)N([R])C1=O</smiles><smiles>[R][R]1ccc(C2CC(=O)NC2=O)cc1</smiles>

2015 年, 本课题组杨振华等 ${ }^{[17]}$ 报道了化学选择性 调控芳基重氮四氟硼酸盐与马来酰亚胺的选择性加成 反应. 在三氯化钛的作用下发生还原芳基化反应生成 3芳基琥珀酰亚胺，反应收率为 $60 \% \sim 83 \%$. 然而，在氯 化亚铜的催化下可以发生氧化芳基化生成 3-芳基马来 酰亚胺，反应收率为 $78 \% \sim 91 \%$ (Scheme 3).

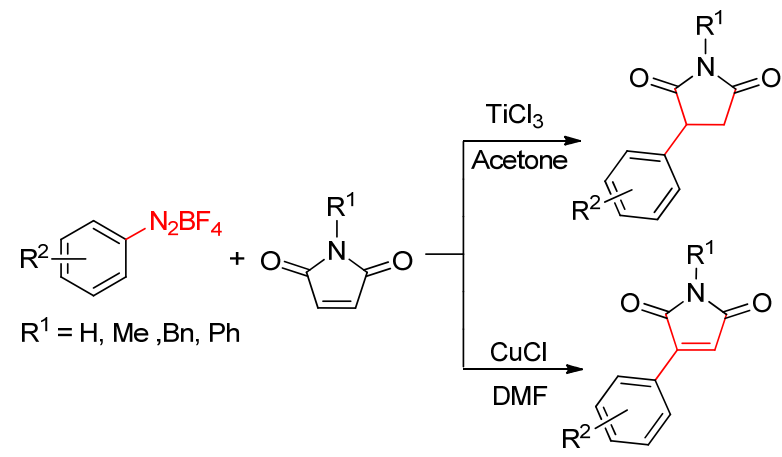

图式 3 芳基重氮四氟硼酸盐与马来酰亚胺的加成反应 Scheme 3 Addition of arenediazonium tetrafluoroborates and maleimides

2015 年, Prabhu 等 ${ }^{[18]}$ 报道了一种新型的铑催化苯乙 酮与马来酰亚胺的 1,4-加成反应. 该反应以乙酰基为定 位基团促进苯环邻位 $\mathrm{C}-\mathrm{H}$ 键与马来酰亚胺反应生成 3芳基琥珀酰亚胺类化合物，收率为 54\% 90\%. 由于羰 基的定位作用使得该反应具有良好的化学选择性, 并且 反应体系中未检测到 Heck 偶联产物和烯醇化加成产物, 其缺点是只适用于 $\mathrm{N}$ 上有取代基的马来酰亚胺类化合 物(Eq. 8).

2018 年, Sundararaju 等 ${ }^{[19]}$ 报道了一种钴催化的芳香 酮邻位 $\mathrm{C}-\mathrm{H}$ 键与马来酰亚胺的芳基化反应. 该反应通 过利用酮羰基的协调定位作用, 实现多种芳香酮邻位 $\mathrm{C}-\mathrm{H}$ 键与马来酰亚胺的加成反应，反应收率为 $27 \%$

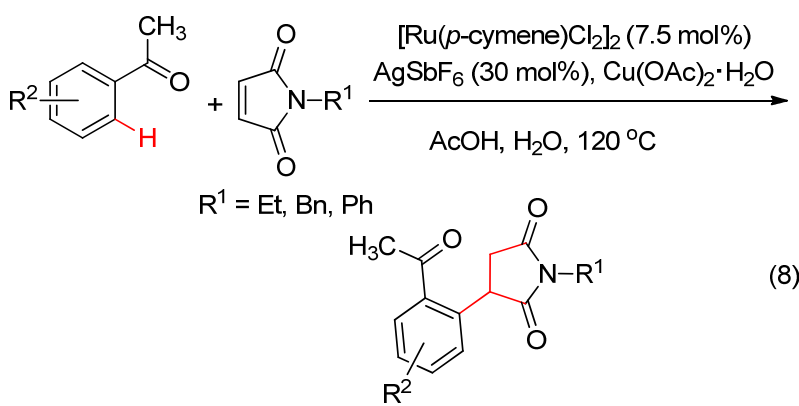

96\% (Eq. 9).

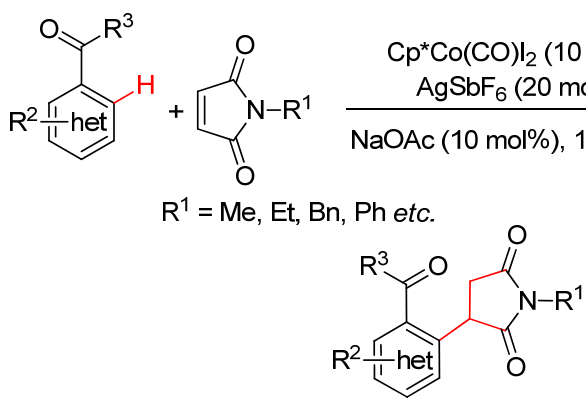

2018 年, Zhang 等 ${ }^{[20]}$ 报道了钉催化的芳香醛邻位 $\mathrm{C}-\mathrm{H}$ 键与马来酰亚胺的芳基化反应. 反应体系中苯胺 和醛反应生成亚胺产生定位作用，产物收率为 $45 \%$ $85 \%$ (Eq. 10).

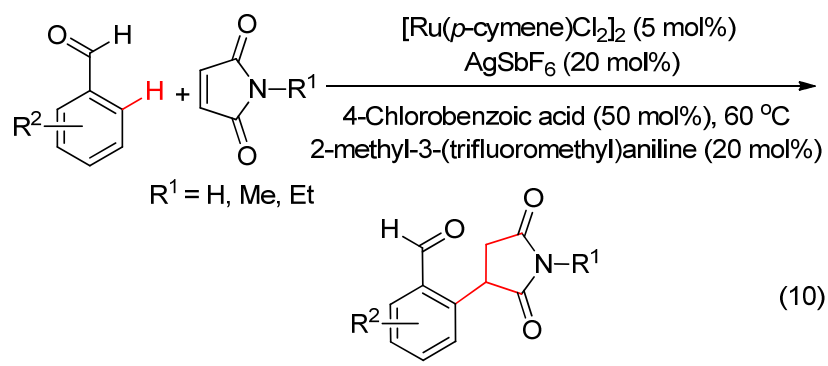

2018 年, Pan 等 ${ }^{[2]}$ 报道了铑催化的 $\alpha, \beta$-不饱和羰基 定位的马来酰亚胺芳基化反应. 由于羰基的定位作用, 芳基邻位的氢优先发生 Michael 加成反应生成 3-芳基琥 珀酰亚胺类化合物，产物为 33\% 86\% (Eq. 11).

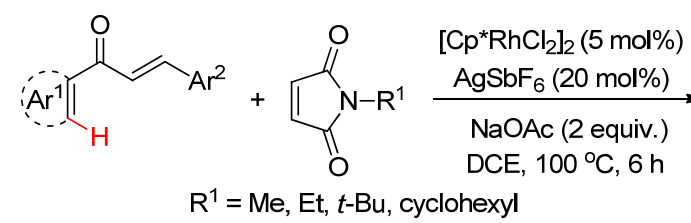<smiles></smiles> 
2016 年, Kim 等 ${ }^{[22]}$ 报道了铑催化的色酮、1,4-萗醌 类、氧杂蒽酮与马来酰亚胺的 Michael 加成反应. 该反 应以羰基为定位基合成一系列含有色酮、䒺醌类和氧杂 葸酮的琥珀酰亚胺，收率为 $36 \%$ ～95\% (Eq. 12).

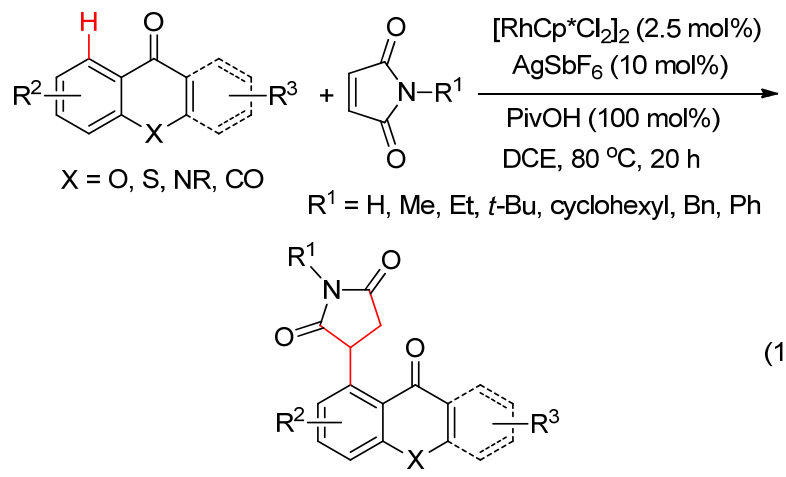

2017 年, Chatani 等 ${ }^{[23]}$ 报道了铑催化的酰胺邻位 C$\mathrm{H}$ 键与马来酰亚胺的芳基化反应. 该反应采用 8-氨基喹 啉为定位基，无需其他任何添加剂，收率为 51\% $100 \%$, 且底物实用范围广, 甚至对于 $\mathrm{N}$ 上未保护的马来 酰亚胺同样适用, 但反应温度较高是其缺点(Eq. 13).

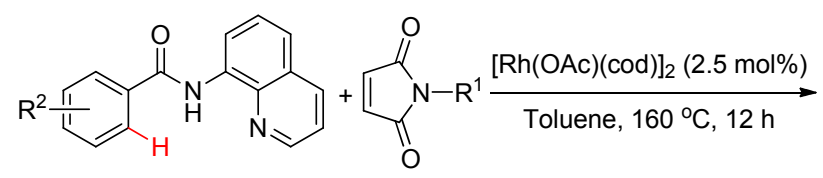
$\mathrm{R}^{1}=\mathrm{H}, \mathrm{Me}$, Et, cyclohexyl, Bn, Ph<smiles>[R][X]c1ccc(C(=O)Nc2cccc3cccnc23)cc1C1CC(=O)N([R])C1=O</smiles>

2018 年, $\mathrm{Wu}$ 课题组 ${ }^{[24]}$ 使用了 $\mathrm{Cp} * \mathrm{Co}(\mathrm{CO}) \mathrm{I}_{2}$ 作催化 剂, 实现了马来酰亚胺和芳基酮肟的芳环 $\mathrm{sp}^{2}-\mathrm{C}-\mathrm{H}$ 键 的共轭加成反应, 得到了一系列琥珀酰亚胺类产物. 该 反应不需要额外加入碱, 收率为 $41 \% \sim 92 \%$, 底物适用 性也很好(Eq. 14).

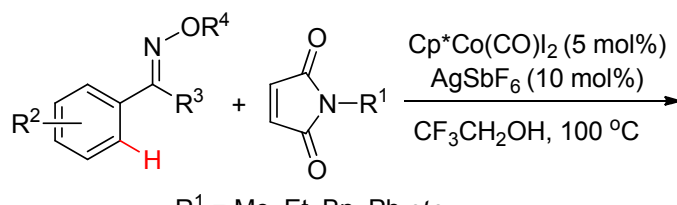<smiles>[R]CN=C([R])c1cc[R1]([R])cc1C1CC(=O)N([R1])C1=O</smiles>

2017 年, Prabhu 等 ${ }^{[25]}$ 报道了一种铑催化的苯甲酸邻 位 $\mathrm{C}$ - $\mathrm{H}$ 键与马来酰亚胺的芳基化反应. 该反应采用羧 酸为定位基，在生成芳基琥珀酰亚胺的同时发生脱羧反 应，收率为 $35 \% \sim 82 \%$, 但是该反应需要 5 equiv. 的乙酸 为添加剂, 且不适用于呋喃、噻唑和吲哚等杂环类化合 物(Eq. 15).

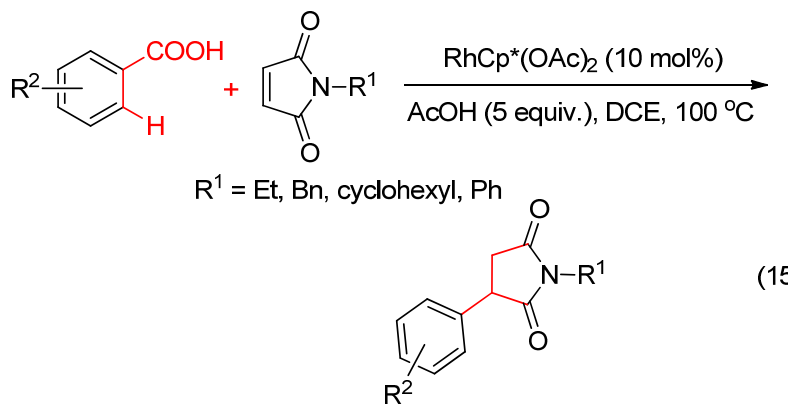

2017 年, Baidya 等 ${ }^{[26]}$ 报道了另一种钉催化的苯甲酸 邻位 $\mathrm{C}-\mathrm{H}$ 键与马来酰亚胺的芳基化反应. 该反应通过 加入三环己基氧化膦 $\left(\mathrm{Cy}_{3} \mathrm{PO}\right)$ 提高钉催化剂反应活性, 进一步提高反应收率至 $60 \% \sim 95 \%$ ，且底物适用范围更 广, 对各种芳环和芳杂环均具有良好的适用性(Eq. 16).

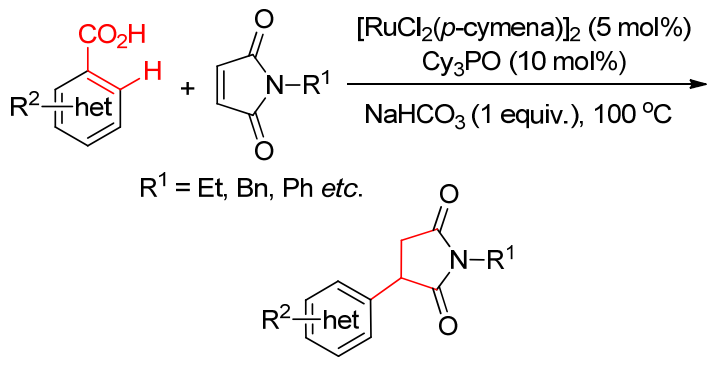

2017 年, Prabhu 等 ${ }^{[27]}$ 又报道了一种钴催化的偶氮苯 与马来酰亚胺的 Michael 加成反应. 该反应采用偶氮基 团为定位基高化学选择性地合成了一系列的芳基琥珀 酰亚胺类化合物, 收率为 $22 \% \sim 94 \%$ (Eq. 17).

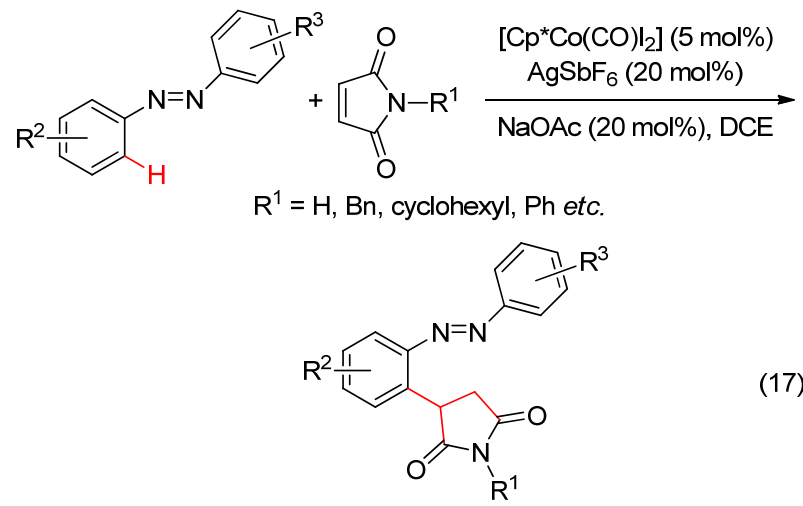

1.1.3 马来酰亚胺与芐位碳原子的 Michael 加成反应 2013 年, Albini 等 ${ }^{[28]}$ 报道了十聚铇酸季铵盐 
(TBADT)光催化剂催化的马来酰亚胺与甲苯的苄基化 反应. 该反应以乙腈/水 $(V: V=5: 1)$ 的混合溶液为反 应溶剂, 同时添加 $0.5 \mathrm{~mol} / \mathrm{L}$ 的高氯酸锂提高其离子浓 度, 光照(310 nm)下反应 $24 \mathrm{~h}$ 可以得到 3-芐基琥珀酰亚 胺, 反应收率为 $46 \% \sim 55 \%$. 该反应对各种 $\mathrm{N}$ 取代的马 来酰亚胺都具有良好的兼容性, 但是反应收率较低(Eq. 18).

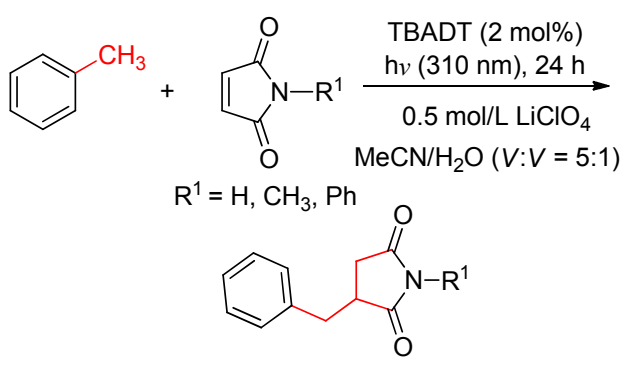

2016 年, Ravelli 等 ${ }^{[29]}$ 也报道了在该催化剂催化下 $N$-苯基马来酰亚胺与苯乙酸的脱羧加成反应. 研究表 明, 苯乙酸可以在光催化下发生脱酸反应产生茮基自由 基, 随后与 $N$-苯基马来酰亚胺发生加成反应生成 3-茮 基琥珀酰亚胺，反应收率为 72\%(Eq. 19).

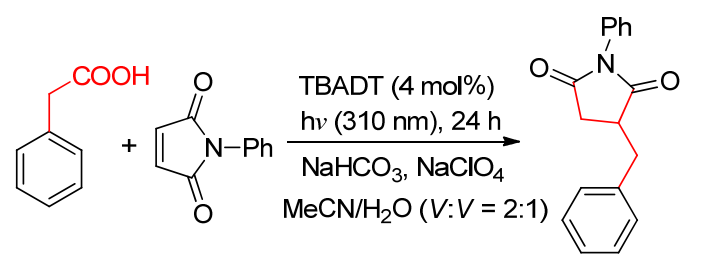

2016 年, $\mathrm{Kim}$ 等 $^{[30]}$ 首次研究了 8-甲基喹啉与马来酰 亚胺的 $\mathrm{sp}^{3}-\mathrm{C}-\mathrm{H}$ 官能化反应. 他们使用 $\mathrm{AgSbF}_{6}$ 和金刚 烷甲酸 $(\mathrm{AdCOOH})$ 作添加剂, 1,2-二氯乙烷为溶剂, $70{ }^{\circ} \mathrm{C}$ 下反应 $24 \mathrm{~h}$, 得到加成产物的最高收率可达 $96 \%$. 该反 应具有良好的官能团耐受性和广泛的底物适用性, 在喹 啉环上任意位置带有吸电子基或供电子基均可发生反 应，且具有较好的收率(Eq. 20).

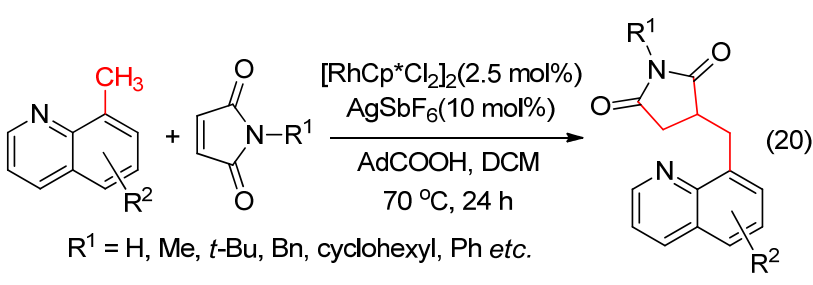

1.1.4 马来酰亚胺与羰基化合物的不对称 Michael 加 成反应

通常，马来酰亚胺与含活泼亚甲基化合物发生 Michael 加成反应, 生成琥珀酰亚胺类化合物 ${ }^{[31]}$, 但近 年来随着手性合成技术的发展, 其不对称 Michael 加成 反应有了很大进展，取得了较好的实验结果.

2007 年, Zhao 等 ${ }^{[32]}$ 报道了手性二苯脯氨醇催化醛
类对马来酰亚胺类化合物的不对称 Michael 加成反应. 琥珀酰亚胺类产物收率为 $21 \% \sim 96 \%$, ee 值为 $51 \%$ 99\% (Eq. 21).

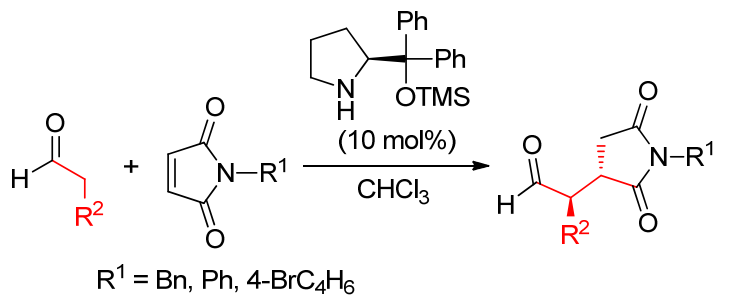

2010 年, $Y e$ 等 ${ }^{[33]}$ 首次报道了由一种高效的双功能 硫脲伯胺手性催化剂催化 $N$-取代马来酰亚胺和 $\alpha, \alpha$-二 取代醛的不对称 Michael 加成反应. 该方法是用 10 $\mathrm{mol} \%$ 的手性二胺作为催化剂, 加入 $10 \mathrm{~mol} \%$ 的苯甲酸, 于二氯甲烷中室温下反应得到含有一个手性季碳中心 的产物, 收率 $85 \% \sim 99 \%$, ee 值为 $91 \% \sim 99 \%$ (Eq. 22).

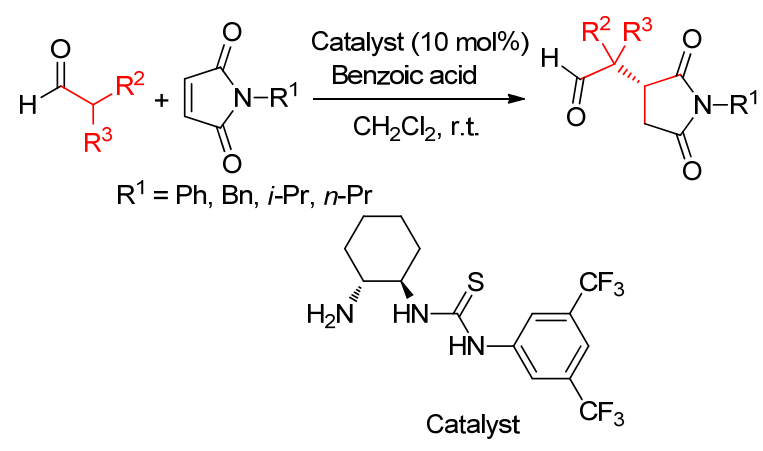

同年，该课题组还报道 ${ }^{[34]}$ 了马来酰亚胺和酮的不 对称 Michael 加成反应. 他们将上述催化剂进行了稍微 改变, 使用了 $10 \mathrm{~mol} \%$ 的 $(R, R)-N-(2,6$-二氯苯磺酰基)1,2 -二苯基乙二胺来催化反应，同样以苯甲酸为添加剂, 甲苯为溶剂在室温下反应，以 $62 \%$ ～99\%收率得到了一 系列 Michael 加成产物, ee 值为 $91 \%$ ～99\%.

2013 年, Zhao 等 ${ }^{[35}$ 报道了奎尼丁硫脲和 $L-2$-氯苯基 甘氨酸作为催化剂可以有效催化醛、酮与马来酰亚胺的 不对称 Michael 加成反应，收率为 $71 \% \sim 99 \%, e e$ 值为 $89 \% \sim 99 \%$. 其缺点是该反应体系仅仅适用于 $N$-取代的 马来酰亚胺(Eq. 23).

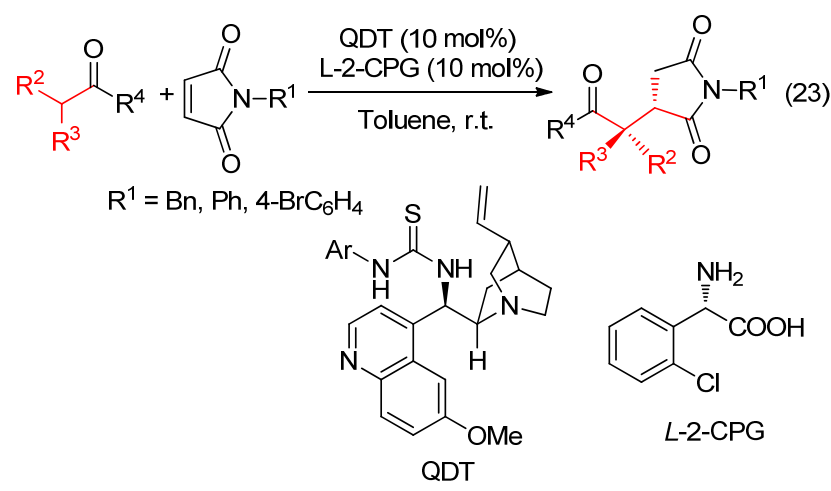


2015 年, Gomez-Bengoa 等 ${ }^{[36]}$ 合成了手性的 $(S, S)$-反 式环己基胺-2-氨基嘧啶有机催化剂, 它可以在 $\mathrm{DMF} /$ 水 溶液中与己二酸(HDA)共催化促进醛与马来酰亚胺的 不对称 Michael 加成反应, 反应收率为 70\% 92\%, ee 值 为 $60 \% \sim 93 \%$. 其优点是 $\mathrm{NH}$-马来酰亚胺也能发生该反 应(Eq. 24).

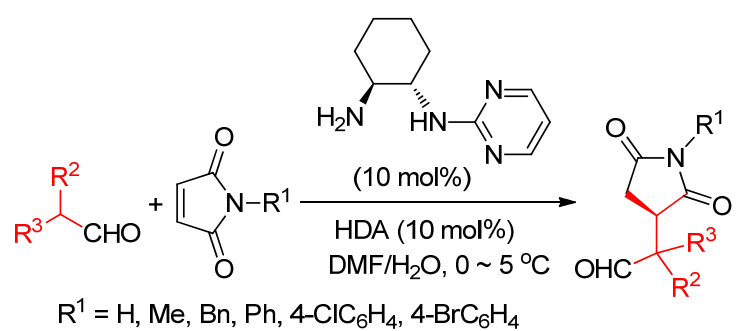

2015 年, Miura 等 ${ }^{[37]}$ 报道了一种新型二氨基亚甲基 狮满二酮(DMI), 它能够有效催化酮与马来酰亚胺的不 对称 Michael 加成反应. 该反应收率为 $51 \% \sim 92 \%$, 且 对映选择性较好, ee 值为 $85 \% \sim 99 \%$, 但底物兼容性较 差(Eq. 25).

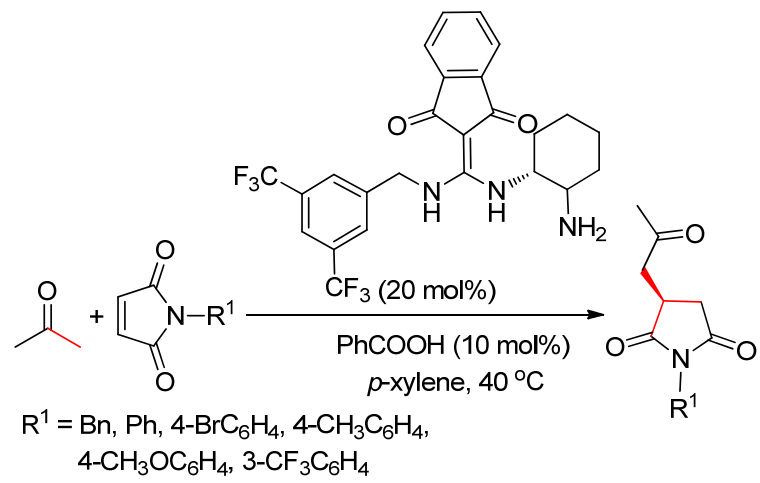

2011 年, Yan 课题组 ${ }^{[38]}$ 报道了氰基乙酸酯和马来酰 亚胺的不对称 Michael 加成反应. 通过对几种金鸡纳碱 类和氨基硫嫝类手性催化剂的篮选, 发现对反应的催化 效果最佳的还是上述手性叔胺硫脲类 Takemoto 催化剂, 以 $86 \% \sim 99 \%$ 收率得到了一系列加成产物, ee 值为 $89 \% \sim 99 \%$ (Eq. 26).

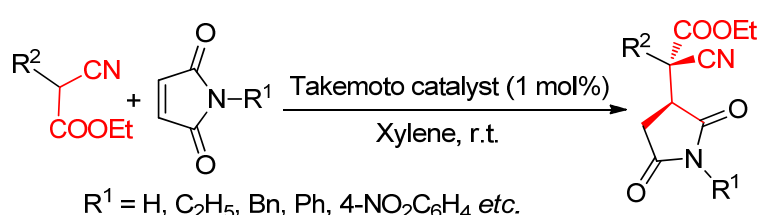

$\mathrm{R}^{1}=\mathrm{H}, \mathrm{C}_{2} \mathrm{H}_{5}, \mathrm{Bn}, \mathrm{Ph}, 4-\mathrm{NO}_{2} \mathrm{C}_{6} \mathrm{H}_{4}$ etc.<smiles>CN(C)C1CCCC[C@H]1NC(=S)Nc1cc(C(F)(F)F)cc(C(F)(F)F)c1</smiles>

2012 年, Wang 等 ${ }^{[39]}$ 报道了一种手性的双官能化硫
脲一叔胺催化的 $\alpha$-取代的异腈基乙酸酯与马来酰亚胺的 不对称加成反应。该反应收率为 $63 \% \sim 98 \%$, 且具有良 好的收率和高度的对映选择性, ee 值为 $72 \% \sim 94 \%$, 生 成的手性琥珀酰亚胺衍生物可以进一步转化为 h5-HT1d 受体拮抗剂(Eq. 27).

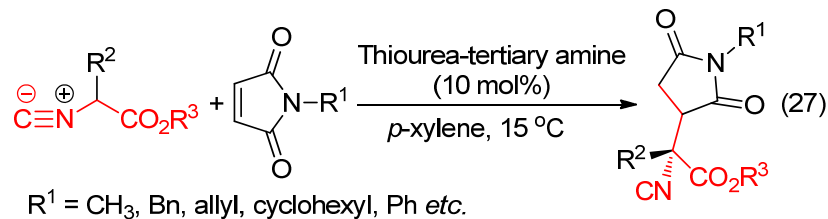<smiles>FC(F)(F)c1cc(NC(=S)N[C@H]2CCCCC2N2CCCC2)cc(C(F)(F)F)c1</smiles>

除此之外, 2011 年, Maruoka 等 ${ }^{[40]}$ 报道了 $\alpha$-取代的 硝基乙酸酯与 $N$-苠基马来酰亚胺的不对称 Michael 加成 反应. 该反应采用哌啶衍生物为催化剂, 在中性相转移 条件下合成一系列不对称加成产物，收率为 $42 \% \sim 92 \%$, $e e$ 值为 $83 \sim 91 \%$, 再经锌粉还原可用于合成 $\alpha, \alpha$-双取代 的 $\alpha$-氨基酸衍生物(Eq. 28).<smiles>[R]OC(=O)C([R])[N+](=O)[O-]</smiles>

2011 年, Najera 等 ${ }^{[41]}$ 报道了手性 C2-对称的双(2-氨 基苯并咪唑)催化的 1,3-二羰基化合物与马来酰亚胺的 共轭加成反应，收率 $69 \% \sim 100 \%$, ee 值为 $78 \% \sim 99 \%$. 该方法成功实现克级规模 Michael 加成产物的合成, 并 且手性有机催化剂可以循环使用，部分原料收率可以实 现定量转化(Eq. 29).

2010 年, Cheng 等 ${ }^{[42]}$ 同样使用一种手性双功能硫艮 叔胺类催化剂催化了 $N$-取代马来酰亚胺和 3-苯基苯并 呋喃-2(3H)-酮的不对称 Michael 加成反应. 该方法是以 $10 \mathrm{~mol} \%$ 的氨基硫脲为催化剂, 在 $4 \AA$ 分子笁的存在下 于 $-80{ }^{\circ} \mathrm{C}$ 的二氯甲烷中反应, 得到 Michael 加成产物, 收率为 $88 \% \sim 99 \%$, ee 值为 91\% 99\% (Eq. 30). 


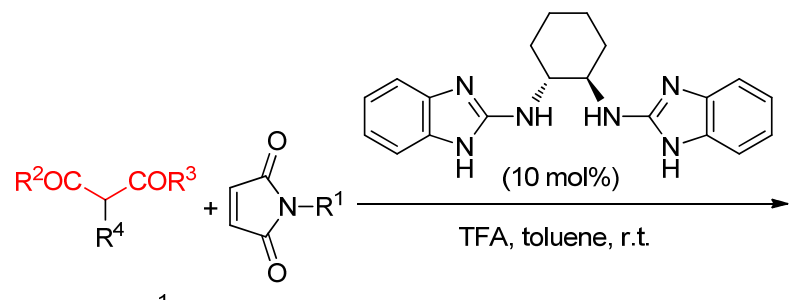

$\mathrm{R}^{1}=\mathrm{H}, \mathrm{CH}_{3}, \mathrm{Bn}, \mathrm{Ph}, 4-\mathrm{BrC}_{6} \mathrm{H}_{4}$<smiles>[R1]N1C(=O)C[C@H](C([R20])([R20])[R20])C1=O</smiles>

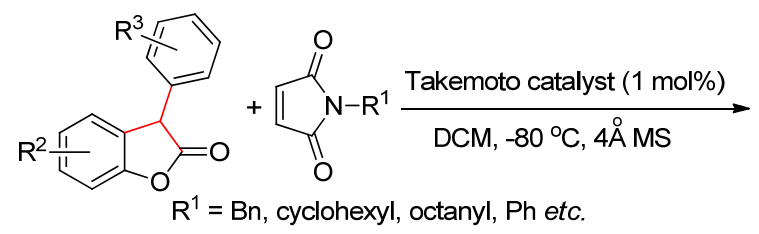<smiles>[R][R]1cccc2c1OC(=O)C2(c1ccccc1)[C@H]1CC(=O)N([R])C1=O</smiles>

2010 年, Yuan 等 ${ }^{[43]}$ 首次尝试以手性的双官能化硫 脲一叔胺为催化剂, 实现了 3-取代二氢吲哚酮衍生物和 马来酰亚胺的不对称 Michael 加成反应. 该反应收率为 $36 \% \sim 92 \%$, 具有良好的立体选择性和对映选择性, ee 值为 $85 \% \sim 98 \%$ (Eq. 31). 但缺点是吲哚酮的 1-位只有 被 Boc 保护时才具有较好的反应活性，限制了该反应的 应用范围。

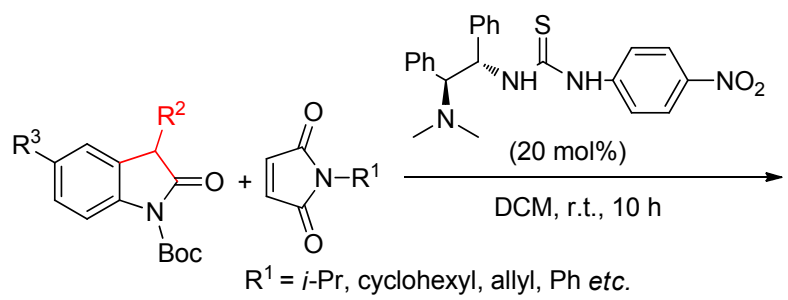<smiles>[R]c1ccc2c(c1)C([R])([C@H]1CC(=O)N([R])C1=O)C(=O)N2C(=O)OC(C)(C)C</smiles>

2015 年, Feng 等 ${ }^{[44]}$ 进一步研究了未保护的 3-取代二 氢吲哚衍生物和马来酰亚胺的不对称 Michael 加成反应. 发现 $N, N^{\prime}$-二氧化物和三氟甲磺酸钪的络合物 $\left(L-\mathrm{RaPr}_{3}-\right.$ $\left.\mathrm{Sc}(\mathrm{OTf})_{3}\right)$ 能够有效催化未保护 3-取代氧化吲哚衍生物 和马来酰亚胺的不对称加成反应. 该反应收率为 $88 \%$ $99 \%$, 且具有较好的立体选择性, ee 值为 $88 \% \sim 99 \%$ (Eq. 32).

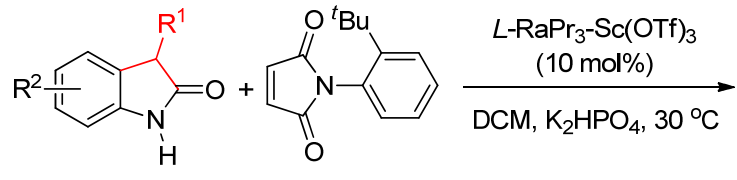

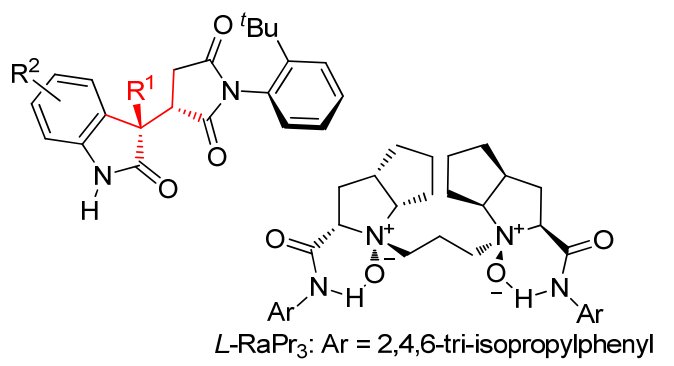

2018 年, Reddy 等 ${ }^{[45]}$ 报道了 2-羧酸酯取代的氧化吲 哚与马来酰亚胺的不对称 Michael 加成反应. 该反应采 取手性双官能团化的方酰胺为有机催化剂, 顺利实现了 3-氧化吲哚 2 位与马来酰亚胺的不对称加成反应. 该体 系收率为 $55 \% \sim 98 \%$, ee 值为 $60 \% \sim 99 \%$, 且具有反应 条件温和、收率高和对映选择性好等优点，同时适用于 $\mathrm{NH}$ 未保护的 3-氧化吲哚类化合物(Eq. 33).

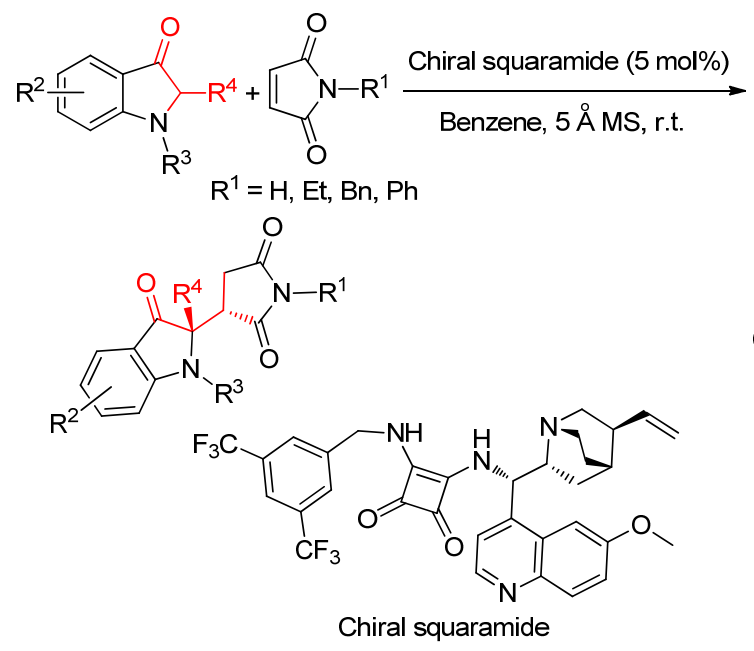

2016 年, Jiang 等 ${ }^{[46]}$ 报道了缩二氨酸的手性叔胺 (DP-UAA)催化 5H-噻唑烷-4-酮和噁唑烷-4-酮与马来酰 亚胺的不对称共轭加成反应. 该反应可高收率地合成一 系列含杂环类化合物，收率为 $82 \% \sim 98 \%$, 并且具有良 好的立体选择性, ee 值为 98\% 99\% (Eq. 34).

\subsection{5 马来酰亚胺与苯喼酸类化合物的 Michael 加成 反应}

2007 年, Iyer 等 ${ }^{[47]}$ 报道了铑催化剂催化芳基硼酸与 马来酰亚胺类化合物的 Michael 加成反应, 该反应在 $50{ }^{\circ} \mathrm{C}$ 反应 3 6 h 可以生成消旋体的 3-芳基琥珀酰亚胺, 反应收率为 $34 \% \sim 80 \%$. 后期经过改进, 将反应在微波 条件下于 $100{ }^{\circ} \mathrm{C}$ 反应 5 $15 \mathrm{~min}$, 得到 3-芳基琥珀酰亚 胺, 收率为 $55 \% \sim 85 \%$ (Eq. 35). 


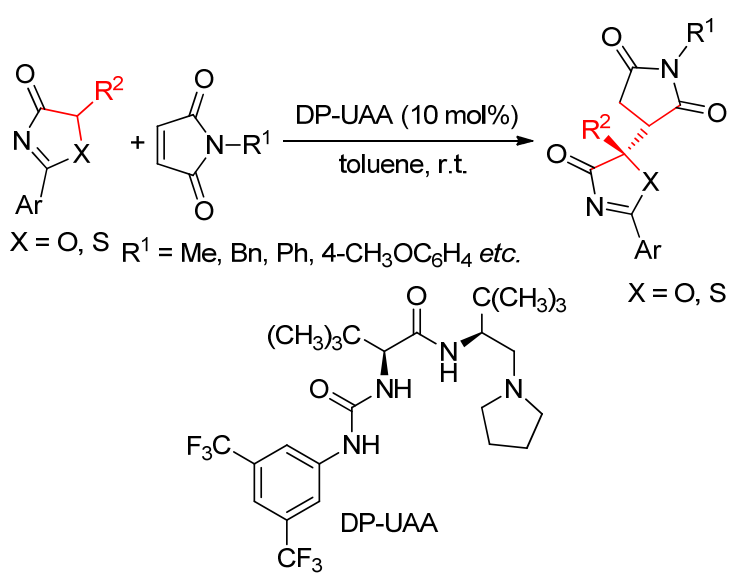

$\underbrace{\mathrm{NH}}_{\mathrm{O}}+\mathrm{Ar}^{1} \mathrm{~B}(\mathrm{OH})_{2} \frac{\left[\mathrm{RhCl}(\mathrm{cod})_{2}\right](5 \mathrm{~mol} \%)}{\mathrm{KOH}, \text { dioxane/ } / \mathrm{H}_{2} \mathrm{O}} \mathrm{Ar}^{1} \overbrace{\mathrm{O}}^{\mathrm{NH}}$

2005 年, Hayashi 等 ${ }^{[88]}$ 报道了在含有碳碳双键的手 性磷二齿配体下, 铑催化剂催化芳基硼酸对马来酰亚胺 类化合物的不对称 Michael 加成反应，不同取代的芳基 嗍酸和马来酰亚胺类化合物反应性良好, 得到的芳基取 代的琥珀酰亚胺类产物收率为 $88 \% \sim 98 \%$, ee 值为 $88 \% \sim 95 \%$ (Eq. 36 ).

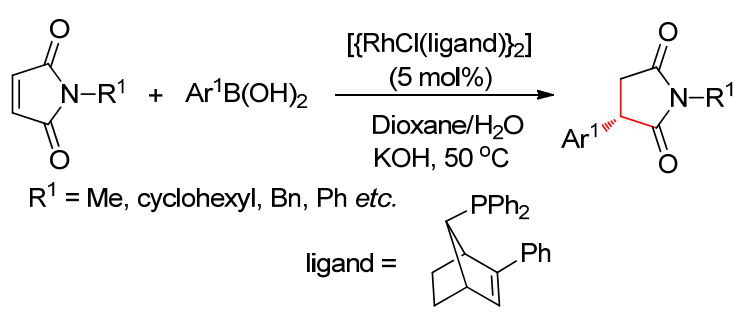

2011 年, Ratovelomanana-Vidal 等 ${ }^{[49}$ 报道了铑催化 的芳香硼酸与马来酰亚胺的不对称 Michael 加成反应. 该反应采用缺电子的二磷化物为配体, 对映选择性地合 成 3-芳基取代的马来酰亚胺类化合物，收率大多为 75\% 以上, ee 值可达 $93 \%$. 但是以 $\mathrm{NH}$ 未保护的马来酰亚胺 原料, 反应收率较低(Eq. 37).

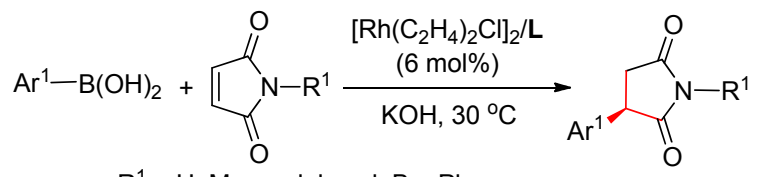
$\mathrm{R}^{1}=\mathrm{H}, \mathrm{Me}$, cyclohexyl, Bn, Ph

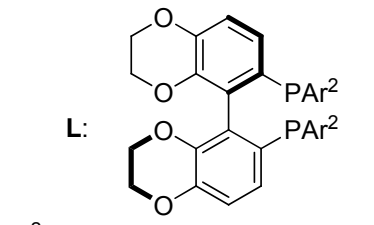

$A r^{2}=3,5$-bis(trifluoromethyl)phenyl
2013 年, Korenaga 等 ${ }^{[50]}$ 报道了 $[\mathrm{RhOH}(\mathrm{cod})]_{2}$ 催化的 芳基硼酸与马来酰亚胺的不对称加成反应, 使用手性二 苯基磷化合物为配体，收率为 $86 \% \sim 99 \%$, ee 值为 $72 \% \sim 99 \%$. 此外, $\mathrm{NH}$ 未取代的马来酰亚胺也可以获得 良好的反应收率和对映选择性(Eq. 38).

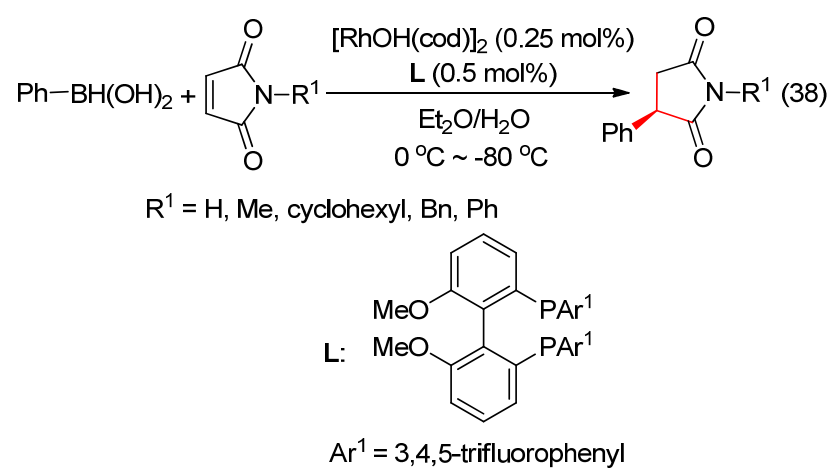

2015 年, $\mathrm{Wu}$ 等 ${ }^{[51]}$ 报道了 2,5 -二芳基取代的二环 [2.2.1]二烯作为配体促进铑催化芳香硼酸和马来酰亚胺 的对映选择性加成反应. 该反应收率为 $72 \% \sim 99 \%$, 且 具有良好的收率和较高的对映选择性, ee 值为 $88 \%$ 98\% (Eq. 39). 此外, 所合成的琥珀酰亚胺还可以经氢 化铝锂还原, 生成合成 HSD-1 抑制剂前体吡咯烷类化 合物.

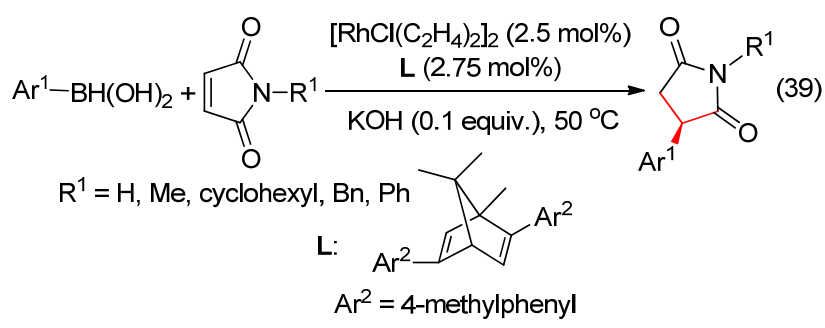

\section{2 马来酰亚胺与杂原子的 Michael 加成反应}

1.2.1 马来酰亚胺与 $\mathrm{O} 、 \mathrm{~S}$ 原子的 Michael 加成反应 通常在不加催化剂的条件下, 硫酚可以与马来西亚 胺发生 Michael 加成, 而醇不与马来酰亚胺发生反应. 2011 年, Nair 等 ${ }^{[52]}$ 报道了 $N$-芳基马来酰亚胺和硫酚(醇) 的 Michael 加成反应. 该反应不需要任何催化剂或添加 剂, 以水作溶剂, 在室温下反应 $15 \mathrm{~min}$, 高收率地得到 硫代琥珀酰亚胺类产物，收率为 $80 \% \sim 96 \%$ (Eq. 40). 2018 年, Keillor 等 ${ }^{[33]}$ 对反应机理进行了深入研究, 对反 应能量进行了计算.<smiles>[R]SC1C(=O)N(c2ccc([R])cc2)C(=O)C1S[R]</smiles>

2012 年, Xia 等 ${ }^{[54]}$ 报道了对甲基苯磺酸 1-甲基咪唑 
盐([Hmim]Ots)离子液体催化含 $\mathrm{O}$ 或 $\mathrm{S}$ 杂原子的亲核试 剂与马来酰亚胺类化合物的 Michael 加成反应, 反应在 无溶剂条件下进行, 使用催化量的离子液体作为催化 剂, 对甲氧基苯硫酚和甲醇分别与 $N$-苯基马来酰亚胺 反应得到取代琥珀酰亚胺类化合物的收率分别为 $91 \%$ 和 $65 \%$ (Eq. 41$)$.

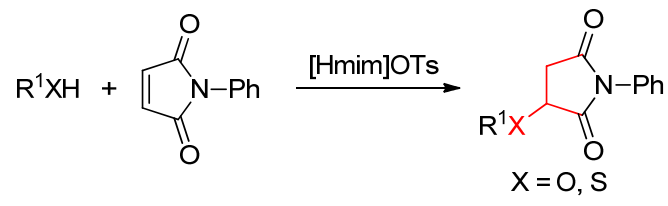

2015 年, 我们课题组安玉龙等 ${ }^{[55]}$ 研究了 Lewis 酸催 化的马来酰亚胺和氧、硫、氮等杂原子的 Michael 加成 反应. 他们发现在 $\mathrm{BF}_{3} \cdot \mathrm{OEt}_{2}$ 催化下在 1,2 -二氯乙烷中, 马来酰亚胺和硫醇或者胺类化合物发生 Michael 加成反 应得到 3-取代琥珀酰亚胺类化合物, 收率为 34\% 91\%。 当马来酰亚胺和烷基醇在二氯甲烷中回流反应时, 得到 的产物为 1,2-Michael 加成产物, 收率 42\% 95\%, 这也 是对 Lewis 酸催化马来酰亚胺的 1,2-加成反应的首次报 道. 与碱催化的方法相比, 该方法操作简单, 反应条件 温和(Scheme 4).

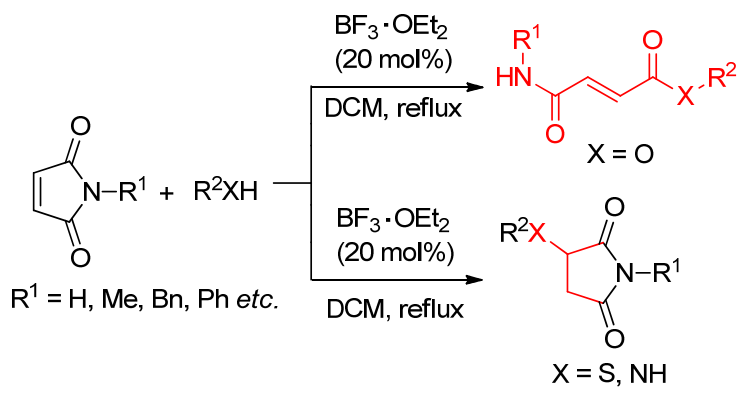

图式 4 马来酰亚胺的杂 Michael 加成反应

Scheme 4 Hetero-Michael addition of maleimides

\subsection{2 马来酰亚胺与 $\mathrm{N}$ 原子的 Michael 加成反应}

2007 年, Rogal 等 ${ }^{[56]}$ 报道了马来酰亚胺和芳伯胺的 Michael 加成反应, 在异丙醇中通过加热得到了 3-取代 马来酰亚胺产物(Eq. 42).

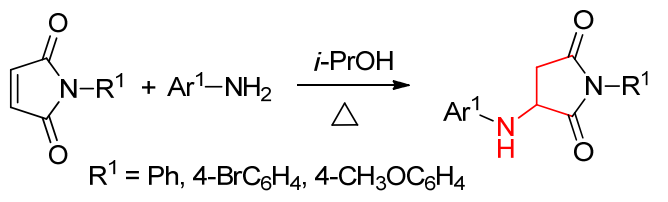

2018 年, Scheidt 等 ${ }^{[57]}$ 报道了 Lewis 酸和胺碱共催化 的胺类与马来酰亚胺类的共轭加成反应. 该反应进一步 提升了反应速率和转化率. 并且被成功应用于合成克唑 替尼一荧光探针. 同年, 该课题组 ${ }^{[58]}$ 报道了使用手性钙 与磷酸络合物 $\mathrm{Ca}(\mathrm{CPA})_{2}$ 催化胺与马来酰亚胺的不对称
Michael 加成反应，构建手性 3-氨基琥珀酰亚胺类化合 物，收率为 $49 \% \sim 96 \%$ (Scheme 5).
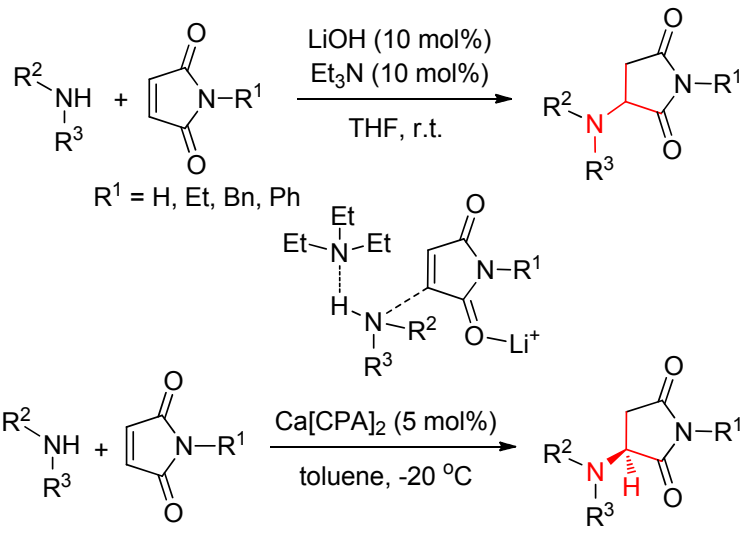
$\mathrm{R}^{1}=\mathrm{Et}, \mathrm{Bn}, \mathrm{Ph}$ etc.

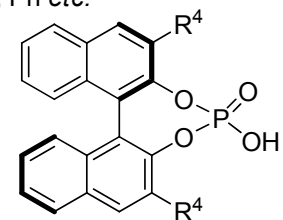

CPA: $R^{4}=9$-phenanthracene

图式 5 胺与马来酰亚胺的共轭加成

Scheme 5 Conjugate addition of amines to maleimide

\subsection{3 马来酰亚胺与 $\mathrm{P}$ 原子的 Michael 加成反应}

2007 年, Tan 及其团队 ${ }^{[59]}$ 研究了 $N$-取代基马来酰亚 胺分子上碳磷键的构造方法. 在 $1,5,7$-三氮杂二环[4.4.0]癸-5-烯(TBD)的催化下，以甲苯作溶剂，室温下 马来酰亚胺可以与二苯基膦酸酯或二苯氧膦反应，得到 加成产物，收率 73\% 99\%。该反应无需金属催化剂， 条件温和，反应速度快，且效率高(Eq. 43)

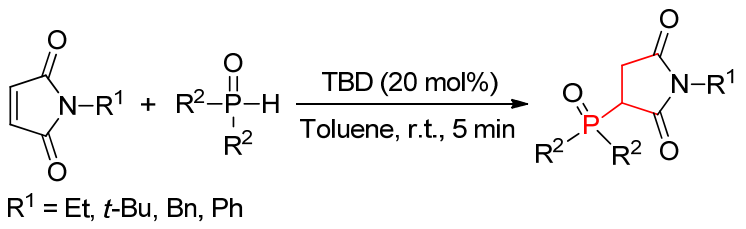

2012 年, Keglevich 课题组 ${ }^{[60]}$ 对上述反应进行了改 进. 他们在微波作用下 $N$-甲基或 $N$-苯基马来酰亚胺能 与亚膦酸二烷基酯、二苯氧基膦等含磷化合物于 $175{ }^{\circ} \mathrm{C}$ 反应 $2.5 \sim 3 \mathrm{~h}$, 得到了一系列的含磷琥珀酰亚胺类产物. 该反应的优点是不需要溶剂和催化剂, 但是缺点是反应 温度较高(Eq. 44)

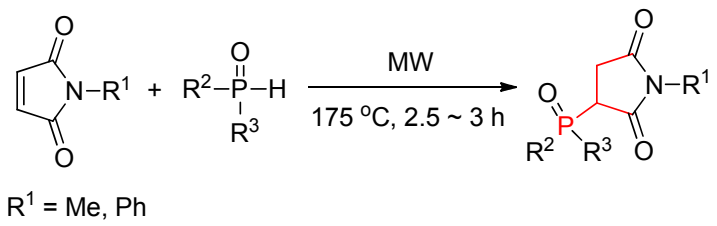


2016 年, Kong 等 ${ }^{[6]}$ 报道了 $N$-杂环膦酸酯-硫腿化合 物作为磷基化试剂与马来酰亚胺发生硫杂-Michael 加成 反应, 合成了 1 -芳基-2,5-二氧吡咯烷基膦酸酯类化合 物, 收率为 $44 \% \sim 92 \%$. 该反应无需任何催化和添加剂, 且反应条件温和(Eq. 45).

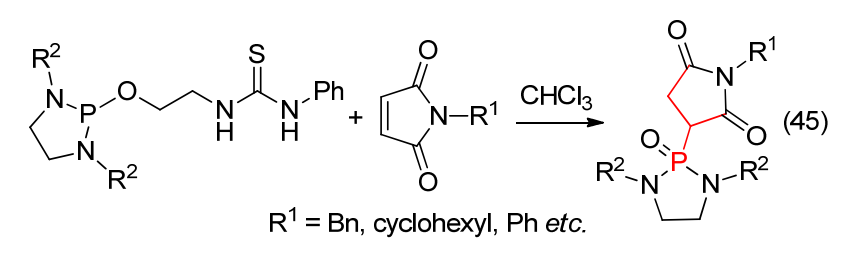

\section{2 马来酰亚胺双键的交叉偶联反应}

马来酰亚胺为含有缺电子的环内烯烃, 与末端烯烃 和脂肪族烯烃相比, 其偶联反应活性相对较低. 通常采 用 3,4-溴代的马来酰亚胺与芳基硼酸或末端炔烃发生偶 联反应 ${ }^{[62]}$. 但是, 由于众多天然有机药物分子中都含有 马来酰亚胺骨架, 所以探究马来酰亚胺在偶联反应中的 可能性具有重要意义. 近年来, 有关马来酰亚胺的偶联 反应已经取得了一些进展.

2008 年, Roshchin 等 ${ }^{[63]}$ 报道了氯化钯催化取代的碘 苯与马来酰亚胺类化合物的 Heck 反应, 反应收率较低, 为 $28 \% \sim 40 \%$. 反应中使用了 2.5 equiv. 的 HCOOK 作为 碱, 由于马来酰亚胺类化合物遇强碱会发生聚合, 这可 能是导致收率低的原因. $N$-苯基取代的马来酰亚胺比 $\mathrm{N}-\mathrm{H}$ 取代的马来酰亚胺的反应效果好, 吸电子取代的 芳基碘苯反应收率较低, 例如当 $\mathrm{R}^{1}=4-\mathrm{CO}_{2} \mathrm{CH}_{3}, \mathrm{R}^{2}=\mathrm{Ph}$ 时, 收率只有 $28 \%$. 尽管如此, 这是第一个通过 Heck 反 应使得马来酰亚胺类化合物的双键芳基化(Eq. 46).

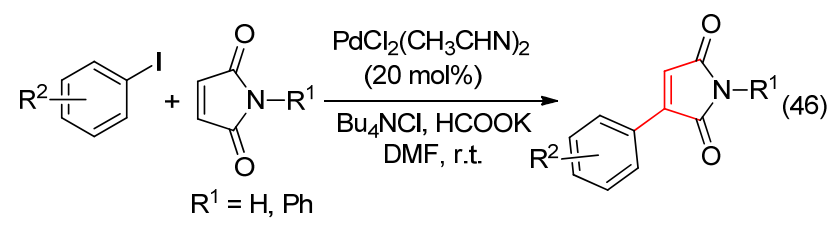

2015 年, Zhou 等 ${ }^{\left[{ }^{[4]}\right.}$ 报道了碘苯与马来酰亚胺的 Heck 偶联反应. 采用碳酸亚乙酯为反应溶剂, 反应收率 为 $74 \% \sim 99 \%$. 但是, 目前该反应仅适用于 $\mathrm{NH}$ 保护的 马来酰亚胺(Eq. 47).

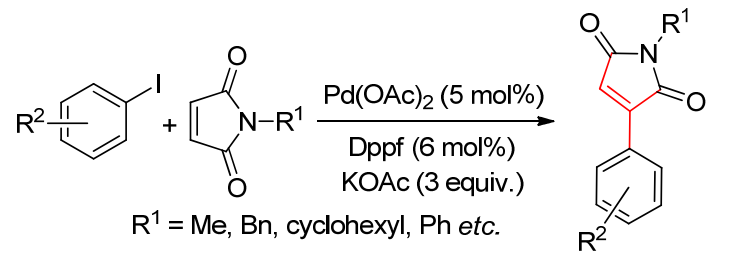

2017 年, Jafarpour 等 ${ }^{[65]}$ 报道了氯化钯催化碘苯与马
来酰亚胺类化合物的 Heck 反应，与 Roshchin 等 ${ }^{[63]}$ 报道 的 Heck 反应不同的是, 该反应得到的是双芳基取代的 马来酰亚胺类化合物, 收率为 $28 \% \sim 88 \%$. 当苯环上有 强吸电子基时收率较低, 有 $\mathrm{NO}_{2}$ 时反应不能进行(Eq. 48).

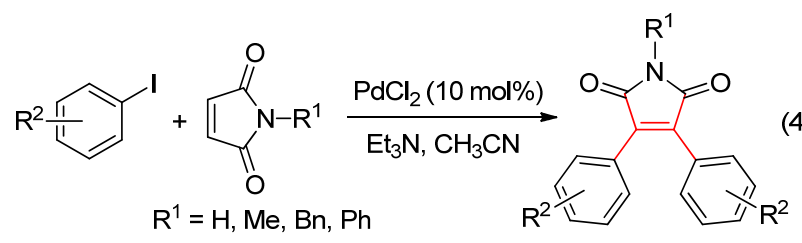

2016 年, Shamsianpour 等 ${ }^{[66]}$ 报道了钯催化的 $N$-取代 马来酰亚胺与芳环的直接脱氢偶联反应. 该反应具有较 高的原子经济性，可以快速合成对称的双取代的芳基马 来酰亚胺类化合物, 收率为 $21 \% \sim 78 \%$ (Eq. 49).

$$
\underset{\mathrm{R}^{1}=\mathrm{Me}, \mathrm{Bn}, \mathrm{Ph}}{\stackrel{\mathrm{PivOH}, \mathrm{TFA}}{110^{\circ} \mathrm{C}, 24 \mathrm{~h}}}
$$

\section{3 马来酰亚胺的氧化偶联反应}

通常马来酰亚胺与胺和硫醇或硫酚化合物发生 Michael 加成反应得到琥珀酰亚胺类化合物. 但在金属 存在下可发生氧化加成反应, 得到 3-取代的马来酰亚胺 类化合物.

2016 年, 我们课题组杨振华等 ${ }^{[67]}$ 报道了铜催化的 硫酚/硫醇和马来酰亚胺的氧化偶联反应. 该反应通过 加入氟硼酸促进铜的催化循环, 减少催化剂的用量. 反 应机理研究表明，该反应涉及加成和氧化脱氢过程，可 以一步构建 3-硫基马来酰亚胺，反应收率为 $60 \% \sim 91 \%$. 此外, 该反应同时适用于 3-吲哚马来酰亚胺与硫酚的氧 化偶联反应，表现出良好的区域选择性(Eq. 50).

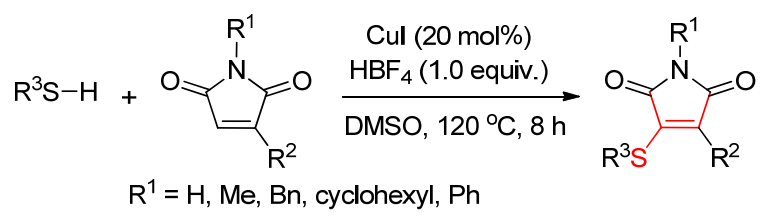

2017 年, Baidya 等 ${ }^{[68]}$ 报道了钉催化的马来酰亚胺与 二苯基二硫(硒)醚或芳基甲酰胺的氧化偶联反应，收率 为 $44 \% \sim 94 \%$. 该反应具有反应条件温和、操作简单和 底物兼容性好等优点(Eq. 51).

2016 年, 我们课题组安玉龙等 ${ }^{[69]}$ 报道了碳酸银和 醋酸铜共催化的马来酰亚胺和胺类化合物的氧化偶联 反应. 该反应可以一步构建 3-氨基马来酰亚胺, 同时还 适用于 3-芳基取代的马来酰亚胺类底物, 反应收率为 


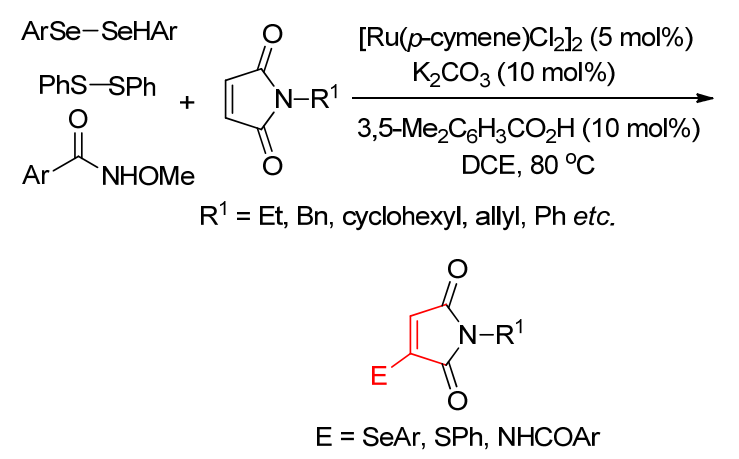

$38 \% \sim 95 \%$ (Eq. 52).

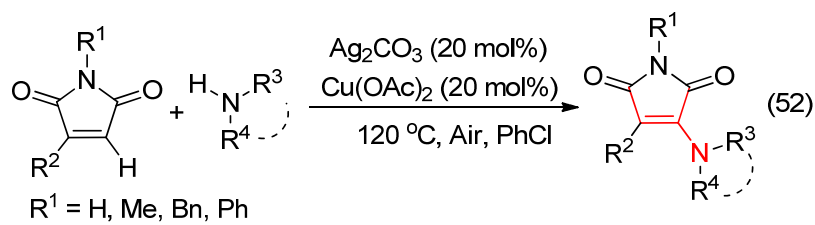

2018 年我们课题组 ${ }^{[70]}$ 又报道了在 $\mathrm{CuBr}_{2}$ 催化下, 以 NBS 为溴源, 马来酰亚胺发生溴氨化反应得到 3-溴-4氨基取代的马来酰亚胺类化合物, 收率为 $62 \%$ ～92\% (Eq. 58.).

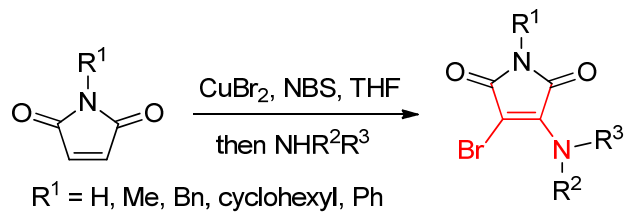

2018 年, 我们课题组杨振华等 ${ }^{[71]}$ 报道了铜催化的 硫酚/硫醇、马来酰亚胺和胺类的三组分氧化偶联反应. 该反应首次实现一锅法构建 3-氨基-4-硫基马来酰亚胺 和噻嗪类化合物, 具有操作简单、原子经济性高等优点, 反应收率为 $27 \% \sim 85 \%$ (Eq. 54). 由于甲胺为气体, 在 上述反应条件下, 甲胺容易溢出, 需要在封管中进行. 为此, 我们用 $\mathrm{DMF}$ 作为甲胺的来源, 以 $\mathrm{CuI}$ 为催化剂, 以 $\mathrm{HBF}_{4}$ 为添加剂使 $\mathrm{DMF}$ 缓慢分解为二甲胺, 发生马来 酰亚胺的硫胺化反应 ${ }^{[71 b]}$.

$$
\mathrm{R}^{2} \mathrm{~S}-\mathrm{H}+
$$

2018 年, 我们课题组杨振华等 ${ }^{[72]}$ 报道了银催化的 吲哚/吡咯、马来酰亚胺和有机磷化合物的三组分偶联反
应. 该反应可以一步实现马来酰亚胺的 $\mathrm{C}-\mathrm{P}$ 双官能团 化，反应收率为 $52 \% \sim 92 \%$. 该反应仅发生在吲哚的 3 位和吡咯的 2 位, 表现出良好的区域选择性(Eq. 55).

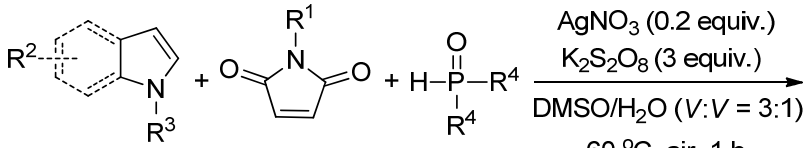

$$
\begin{aligned}
& \mathrm{R}^{1}=\mathrm{H}, \mathrm{Me}, \mathrm{Bn} \text {, cyclohexyl, } \mathrm{Ph} \quad 60^{\circ} \mathrm{C}, \text { air, } 1 \mathrm{~h} \\
& \text { (1) }
\end{aligned}
$$

\section{4 马来酰亚胺双键的环加成反应}

马来酰亚胺中含有不饱和双键可以发生 DielsAlder 反应以及 $[2+2]$ 和 $[3+2]$ 等环加成反应, 在有机合 成、材料和生物医药领域得到较为广泛的应用 ${ }^{[73]}$.

2012 年, Baker 等 ${ }^{[74]}$ 报道了光照下烯烃与 3-硫基取 代的马来酰亚胺类化合物发生 $[2+2]$ 环加成反应, 收率 为 $41 \% \sim 80 \%$ (Eq. 56).

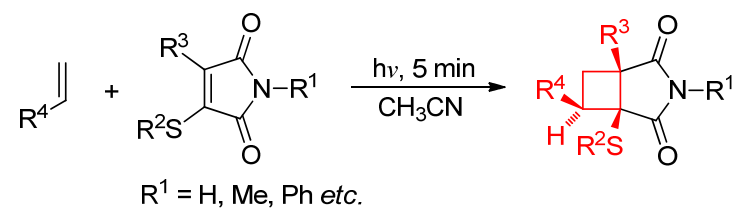

2015 年, Sun 等 ${ }^{[75]}$ 报道了可见光诱导异吲哚啉化合 物形成异吲哚中间体, 再与马来酰亚胺发生 [4+2]环化 反应，收率为 $61 \% \sim 84 \%$, 且反应条件温和，无需过渡 金属催化，具有较高的原子经济性(Eq. 57).

$$
\text { (soindole }
$$

2017 年, Xie 等 ${ }^{[76]}$ 报道了异吲哚酮与二苯基硅氢反 应得到异吲哚, 而后与 $N$-苯基马来酰亚胺发生 DielsAlder 反应，收率为 $24 \% \sim 91 \%$ (Scheme 6). 


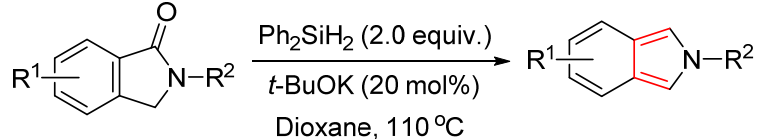

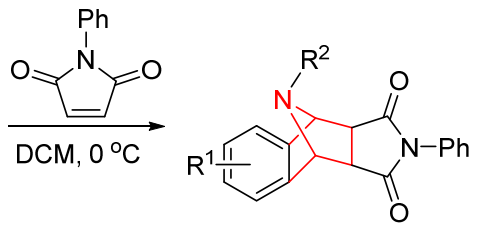

图式 6 异吲哚与马来酰亚胺的 Diels-Alder 反应

Scheme 6 Diels-Alder reaction of isoindoles with maleimides

2016 年, Jiang 等 ${ }^{[77]}$ 报道了使用 Takemoto's 催化剂 催化 $5 H$-噁唑-4-酮与 $N$-取代的马来酰亚胺的[4+2]环化 反应，该反应收率为 $68 \% \sim 90 \%$ (Eq. 58 )。<smiles>[R]C1=NC(=O)C([R2])O1</smiles>

$\mathrm{R}^{1}=\mathrm{Bn}, \mathrm{Ph}, 4-\mathrm{CH}_{3} \mathrm{C}_{6} \mathrm{H}_{4}, 4-\mathrm{ClC}_{6} \mathrm{H}_{4}$, etc.<smiles>[R]C1C2C(=O)NC(=O)C2C([R])C12OC2=O</smiles>

2016年, Hara 等 ${ }^{[78]}$ 报道了一种手性吡啶磷酰胺作为 双布朗斯特酸催化剂催化 1-氨基二烯烃与马来酰亚胺 的对映选择性 Diels-Alder 反应. 该反应收率为 $55 \%$ $99 \%, e e$ 值为 $63 \% \sim 98 \%$ (Eq. 59).

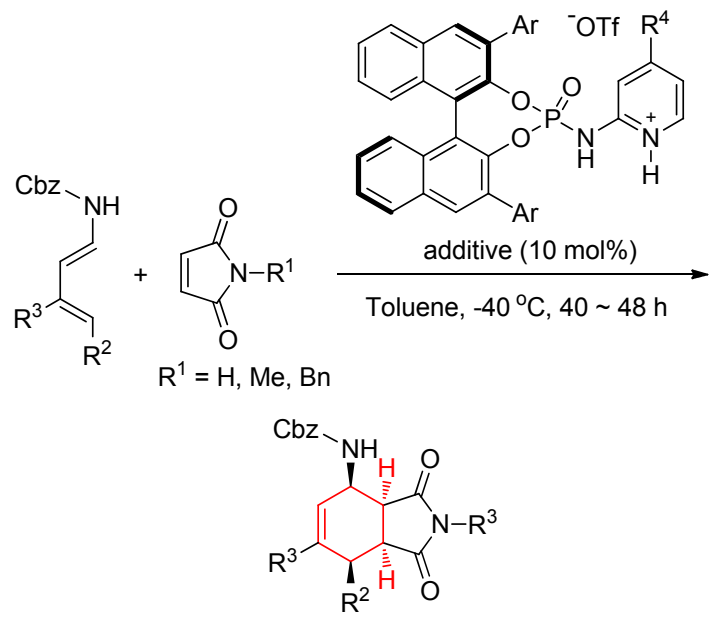

2012 年, Kumar 等 ${ }^{\left[{ }^{[9]}\right.}$ 报道了氯胺-T(CAT)促进的腙 与 $N$-芳基马来酰亚胺的 $[3+2]$ 环加成反应. 该方法将 $N$ -
芳基马来酰亚胺、腙和氯胺- $\mathrm{T}$ 在乙醇中回流 $3 \mathrm{~h}$, 即可 得到 1,3,5-三芳基-4,6-二氧代吡咯并 [3,4- $d]$-7,8-二氢吡 唑，收率为 38\% 66\%，该文献仅报道了 $N$-苯基马来酰 亚胺为反应原料，以其它的 $N$-取代马来酰亚胺作为反 应底物有待进一步研究(Eq. 60).

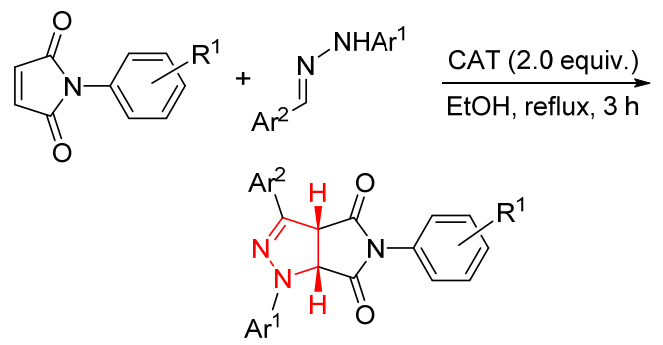

2016 年, Liu 等 ${ }^{[80]}$ 报道了无催化剂条件下 $N$-取代马 来酰亚胺与腙的 $[3+2]$ 环加成反应. $N$-取代马来酰亚胺 与腙在乙醇中回流 $24 \mathrm{~h}$, 得到一系列 $3 a, 6 a$-二氢- $1 H$-吡 咯并 $[3,4-c]$ 吡唑-4,6-二酮衍生物, 测定了它们对 HIV-1 酶的抑制作用(Eq. 61)

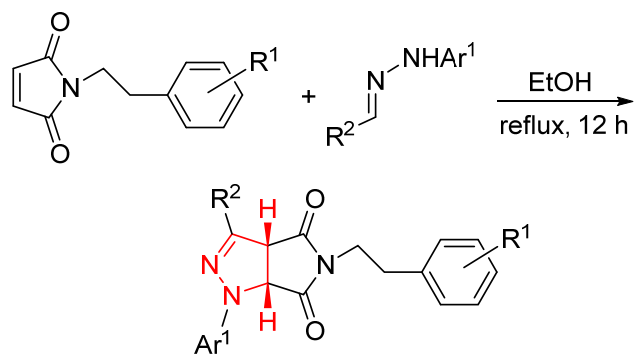

\section{5 马来酰亚胺参与的其它反应}

除上述 Michael加成、氧化偶联和环加成反应外，马 来酰亚胺还可以与双键发生偶联反应，生成螺环或 3-取 代的琥珀酰亚胺类化合物.

2014 年, Shi 等 ${ }^{[81]}$ 报道了一种新型三苯基膦催化的 4,4-二氧基-2-亚甲基-3-丁烯酸酯与 $N$-取代马来酰亚胺 的 $[4+1]$ 环化反应. 该反应可以用于合成五元螺环类化 合物，收率为 $73 \% \sim 95 \%$ (Eq. 62).

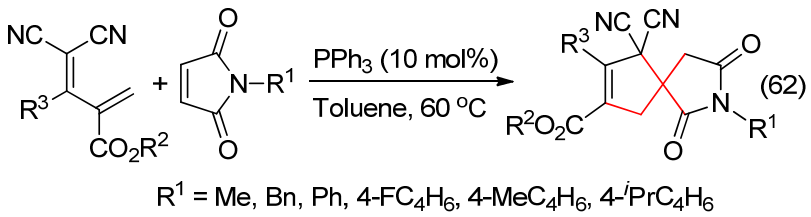

2016 年, Kim 等 ${ }^{[82]}$ 报道了铑催化的丙烯酰胺与马来 酰亚胺的偶联反应. 该反应实现末端烯烃与马来酰亚胺 的直接偶联反应，同时伴随双键的迁移形成亚甲基取代 的琥珀酰亚胺类化合物，收率为 $20 \% \sim 95 \%$. 但是, 3-甲 基取代的马来酰亚胺不能发生反应(Eq. 63). 


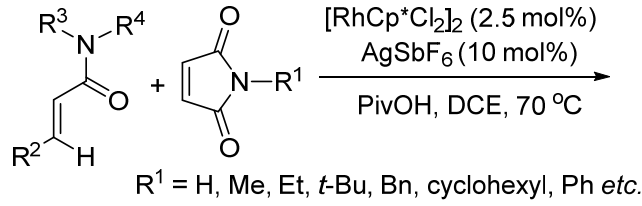<smiles>[R]/C(CC(=O)N([R])[R])=C1/CC(=O)N([R])C1=O</smiles>

2016 年, Miura 等 ${ }^{[83]}$ 报道了钉催化的 $N$-取代马来酰 亚胺与缺电子的烯烃(丙烯酸酯和丙烯酰胺)的偶联反 应，生成亚甲基取代的琥珀酰亚胺类化合物，收率为 $35 \%$ \% $94 \%$. 但该反应并不适用于丙烯腈底物(Eq. 64).

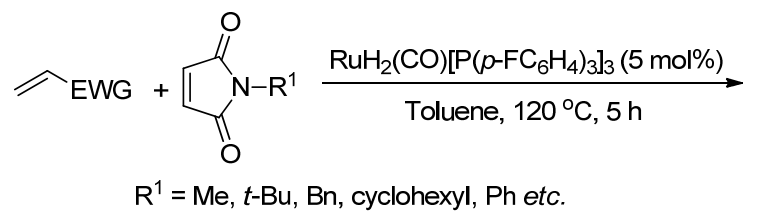<smiles>[R]N1C(=O)C/C(=C\COC(C)(C)C)C1=O</smiles>

2017 年, Zhang 等 ${ }^{[84]}$ 报道了钴催化的马来酰亚胺与 烯胺的偶联反应生成乙烯基取代的琥珀酰亚胺类化合 物. 该反应收率为 $18 \% \sim 91 \%$, 且对 $\mathrm{NH}$ 未保护的马来 酰亚胺具有良好的适用性(Eq. 65).

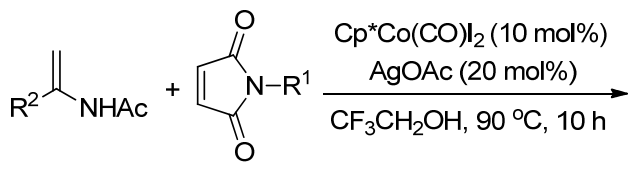

$\mathrm{R}^{1}=\mathrm{H}, \mathrm{Et}, t-\mathrm{Bu}, \mathrm{Bn}$, cyclohexyl, $\mathrm{Ph}$<smiles>[Z10]N/C([R])=C\[C@H]1CC(=O)N([R1])C1=O</smiles>

2012 年, Falck 等 ${ }^{[85}$ 报道了一例铑催化苯甲酰基对 甲苯磺酰胺和 $N$-甲基马来酰亚胺的氧化偶联反应生成 异吲哚啉酮衍生物, 收率为 $73 \%$ (Eq. 66).

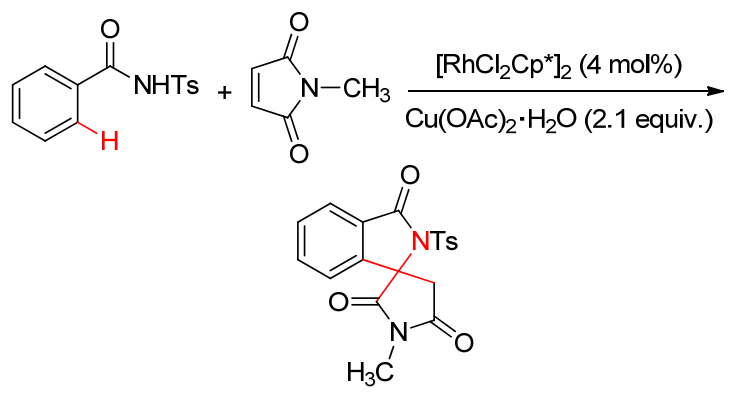

2015 年, Miura 等 ${ }^{[86]}$ 报道了铜催化的苯甲酰胺与马 来酰亚胺的氧化偶联反应，生成含异吲哚酮的琥珀酰亚 胺类化合物. 其中 8-氨基喹啉起辅助作用，二环已基甲 基胺为添加剂，反应收率为 19\%～99\% (Eq. 67).
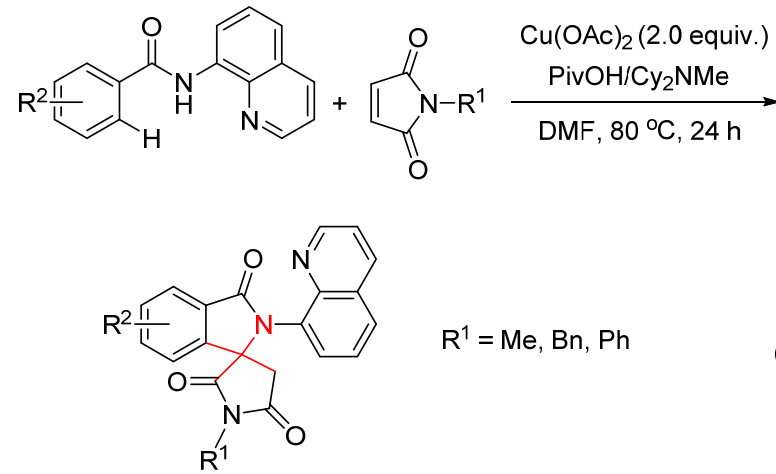

\section{6 结论与展望}

综上所述，马来酰亚胺以其独特的化学结构和生物 活性已成为有机化学研究热点之一. 马来酰亚胺可以与 多种亲核试剂发生 Michael 加成反应, 其中以碳Michael 加成反应为主, 氮杂、硫杂和磷杂-Michael 加成 反应还有待进一步研究. 马来酰亚胺的氧化偶联和环加 成反应，特别是马来酰亚胺双键的双官能化反应，在构 建新型含氮杂环类化合物发挥着重要作用，寻找高效、 环保、可循环使用的催化剂，用于合成具有不对称结构 的天然产物和药物分子，并进一步探索其在生物医药和 新材料领域的应用是其研究方向, 将在今后将得到进一 步的发展.

\section{References}

[1] Lavrard, H.; Rodriguez, F.; Delfourne, E. Bioorg. Med. Chem. Lett. 2014, 22, 1961.

[2] Chien, S.-C.; Chen, M.-L.; Kuo, H.-T.; Tsai, Y.-C.; Lin, B.-F.; Kuo, Y.-H. J. Agric. Food Chem. 2008, 56, 7017.

[3] (a) Ho, S.-Y.; Alam, J.; Jeyaraj, D.-A.; Wang, W.; Lin, G.-R.; Ang, S.-H.; Tan, E.-S.-W.; Lee, M.-A.; Ke, Z.; Madan, B.; Virshup, D.-M.; Ding, L.-J.; Manoharan, V.; Chew, Y.-S.; Low, C.-B.; Pendharkar, V.; Sangthongpitag, K.; Hill, J.; Keller, T.-H.; Poulsen, A. J. Med. Chem. 2017, 60, 6678.

(b) Alam, J.; Poulsen, A.; Ho, S.-Y.; Wang, W.-L.; Duraiswamy, A. WO 2015094118, 2008 [Chem. Abstr. 2015, 163, 132777].

[4] Kayser, S.; Levis, M.-J.; Schlenk, R.-F. Expert Rev. Clin. Pharmacol. 2017, 10, 1177.

(b) Levis, M. Blood 2017, 129, 3403.

[5] Shimokawa, J.; Chiyoda, K.; Umihara, H.; Fukuyama, T. Chem. Pharm. Bull. 2016, 64, 1239.

(b) Cai, S.-L.; Song, R.; Dong, H.-Q.; Lin, G.-Q.; Sun, X.-W. Org. Lett. 2016, 18, 1996.

[6] (a) Daly, M.-J.; Jones, G.-W.; Nicholls, P.-J.; Smith, H.-J.; Rowlands, M.-G.; Bunnett, M.-A. J. Med. Chem. 1986, 29, 520.

(b) Sharma, D.-K.; Rajput, V.-S.; Singh, S.; Sharma, R.; Khan, I. A.; Mukherjee, D. ChemistrySelect 2016, 1, 1954.

[7] (a) Driller, K.-M.; Klein, H.; Jackstell, R.; Beller, M. Angew. Chem., Int. Ed. 2009, 48, 6041.

(b) Mathur, P.; Joshi, R.-K.; Rai, D.-K.; Jha, B.; Mobin, S.-M. Dal- 
ton. Trans. 2012, 41, 5045

[8] Henon, H.; Messaoudi, S.; Hugon, B.; Anizon, F.; Pfeiffer, B.; Prudhomme, M. Tetrahedron 2005, 61, 5599.

[9] An, Y.-L.; Shao, Z.-Y.; Cheng, J.; Zhao, S.-Y. Synthesis 2013, 45, 2719.

[10] Lanke, V.; Bettadapur, K.-R.; Prabhu, K.-R. Org. Lett. 2015, 17, 4662.

[11] Muniraj, N.; Prabhu, K.-R. ACS Omega 2017, 2, 4470.

[12] Zhang, Z.; Han, S.; Tang, M.; Ackermann, L.; Li, J. Org. Lett. 2017, 19,3315 .

[13] Liu, S.-L.; Li, Y.; Guo, J.-R.; Yang, G.-C.; Li, X.-H.; Gong, J.-F.; Song, M.-P. Org. Lett. 2017, 19, 4042.

[14] Sherikar, M.-S.; Kapanaiah, R.; Lanke, V.; Prabhu, K.-R. Chem. Commun. 2018, 54, 11200.

[15] Pan, C.; Wang, Y.; Wu, C.; Yu, J.-T. Org. Biomol. Chem. 2018, 16, 693.

[16] Koltunov, K.-Y.; Prakash, G.-K.-S.; Rasul, G.; Olah, G.-A. Eur. J. Org. Chem. 2006, 4861.

[17] Yang, Z.-H.; Chen, Z.-H.; An, Y.-L.; Zhao, S.-Y. RSC Adv. 2016, 6, 23438.

[18] Bettadapur, K.-R.; Lanke, V.; Prabhu, K.-R. Org. Lett. 2015, 17, 4658.

[19] Mandal, R.; Emayavaramban, B.; Sundararaju, B. Org. Lett. 2018, $20,2835$.

[20] Li, F.; Zhou, Y.; Yang, H.; Liu, D.; Sun, B.; Zhang, F.-L. Org. Lett. 2018, $1,146$.

[21] Yu, J. T.; Chen, R.; Jia, H.; Pan, C. J. Org. Chem. 2018, 83, 12086.

[22] Han, S.-H.; Kim, S.; De, U.; Mishra, N.-K.; Park, J.; Sharma, S.; Kwak, J.-H.; Han, S.; Kim, H.-S.; Kim, I.-S. J. Org. Chem. 2016, $81,12416$.

[23] He, Q.; Yamaguchi, T.; Chatani, N. Org. Lett. 2017, 19, 4544.

[24] Chen, X.; Ren, J.; Xie, H.; Sun, W.; Sun, M.; Wu, B. Org. Chem. Front. 2018, 5, 184.

[25] Bettadapur, K.-R.; Lanke, V.; Prabhu, K.-R. Chem. Commun. 2017, 53,6251 .

[26] Mandal, A.; Sahoo, H.; Dana, S.; Baidya, M. Org. Lett. 2017, 19, 4138.

[27] Muniraj, N.; Prabhu, K.-R. J. Org. Chem. 2017, 82, 6913.

[28] Qrareya, H.; Ravelli, D.; Fagnoni, M.; Albinia, A. Adv. Synth. Catal. 2013, 355, 2891

[29] Capaldo, L.; Buzzetti, L.; Merli, D.; Fagnoni, M.; Ravelli, D. J. Org. Chem. 2016, 81, 7102.

[30] Han, S.; Park, J.; Kim, S.; Lee, S.-H.; Sharma, S.; Mishra, N.-K.; Jung, Y.-H.; Kim, I.-S. Org. Lett. 2016, 18, 4666.

[31] (a) Cunha, S.; Rodovalho, W.; Azevedo, N. R.; Mendonca, M.-D.-O.; Lariucci, C.; Vencato, I. J. Brazil. Chem. Soc. 2002, 13, 629.

(b) Gomez-Torres, E.; Alonso, D.-A.; Gomez-Bengoa, E.; Najera, C. Eur. J. Org. Chem. 2013, 2013, 1434.

(c) Noeth, J.; Frankowski, K.-J.; Neuenswander, B.; Aube, J.; Reiser, O. J. Comb. Chem. 2008, 10, 456.

[32] Zhao, G.-L.; Xu, Y.-M.; Sunden, H.; Eriksson, L.; Sayah, M.; Cordova, A. Chem. Commun. 2007, 7, 734.

[33] Yu, F.; Jin, Z.; Huang, H.; Ye. T.; Liang, X.; Ye, J.-X. Org. Biomol. Chem. 2010, 8, 4767.

[34] Yu, F.; Sun, X.; Jin, Z.; Wen, S.; Liang, X.; Ye, J.-X. Chem. Commun. 2010, 46, 4589.

[35] Muramulla, S.; Ma, J.-A.; Zhao, J.-C.-G. Adv. Synth. Catal. 2013, $355,1260$.

[36] Vizcaino-Milla, P.; Sansano, J.-M.; Najera, C.; Fiser, B.; GomezBengoa, E. Synthesis 2015, 47, 2199.

[37] Nakashima, K.; Kawada, M.; Hirashima, S.; Kato, M.; Koseki, Y.; Miura, T. Synlett 2015, 26, 1248.

[38] Wang, J.-J.; Dong, X.-J.; Wei, W.-T.; Yan, M. Tetrahedron: Asymmetry 2011, 22, 690

[39] Bai, J.-F.; Wang, L.-L.; Peng, L.; Guo, Y.-L.; Jia, L.-N.; Tian, F.; He, G.-Y.; Xu, X.-Y.; Wang, L.-X. J. Org. Chem. 2012, 77, 2947.

[40] Shirakawa, S.; Terao, S. J.; He, R.; Maruoka, K. Chem. Commun.
2011, 47, 10557.

[41] Gomez-Torres, E.; Alonso, D. A.; Gomez-Bengoa, E.; Najera, C. Org. Lett. 2011, 13, 6106.

[42] Li, X.; Hu, S.; Xi, Z.; Zhang, L.; Luo, S.; Cheng, J.-P. J. Org. Chem. 2010, 75, 8697.

[43] Liao, Y.-H.; Liu, X.-L.; Wu, Z.-J.; Cun, L.-F.; Zhang, X.-M.; Yuan, W.-C. Org. Lett. 2010, 12, 2896.

[44] Feng, J.; Zhang, Y.; Lin, L.; Yao, Q.; Liu, X.; Feng, X. Chem. Commun. 2015, 51, 10554.

[45] Yarlagadda, S.; Reddy, C.-R.; Ramesh, B.; Kumar, G.-R.; Sridhar, B.; Reddy, B.-V.-S. Eur. J. Org. Chem. 2018, 1364.

[46] Li, J.; Qiu, S.; Ye, X.; Zhu, B.; Liu, H.; Jiang, Z. J. Org. Chem. 2016, 81, 11916.

[47] Iyer, P.-S.; O'Malley, M.-M.; Lucas, M.-C. Tetrahedron Lett. 2007, $48,4413$.

[48] Shintani, R.; Duan, W.-L.; Nagano, T.; Okada, A.; Hayashi, T. Angew. Chem., Int. Ed. 2005, 44, 4611.

[49] Berhal, F.; Wu, Z.; Genet, J.; Ayad, T.; Ratovelomanana-Vidal, V. J. Org. Chem. 2011, 76, 6320.

[50] Korenaga, T.; Ko, A.; Shimamda, K. J. Org. Chem. 2013, 78, 9975.

[51] Gopula, B.; Yang, S.-H.; Kuo, T.-S.; Hsieh, J.-C.; Wu, P.-Y.; Henschke, J.-P.; Wu, H.-L. Chem. Eur. J. 2015, 21, 11050

[52] Kumar, V.; Mitra, R.; Bhattarai, S.; Nair, V.-A. Synth. Commun. 2011, 41, 392.

[53] Raycroft, M.-A.-R.; Racine, K.-E.; Rowley, C.-N.; Keillor, J.-W. J. Org. Chem. 2018, 83, 11674.

[54] Han, F.; Yang, L.; Li, Z.; Xia, C.-G. Org. Biomol. Chem. 2012, 10, 346.

[55] An, Y.-L.; Deng, Y.-X.; Zhang, W.; Zhao, S.-Y. Synthesis 2015, 47, 1581.

[56] Velchinskaya, E.; Petsushak, B.; Rogal, A. Chem. Heterocycl. Compd. 2007, 43, 695.

[57] Uno, B.-E.; Deibler, K.-K.; Villa, C.; Raghuraman, A.; Scheidt, K.-A. Adv. Synth. Catal. 2018, 360, 1719.

[58] Uno, B.-E.; Dicken, R.-D.; Redfern, L.-R.; Stern, C.-M.; Krzywicki, G.-G.; Scheidt, K.-A. Chem. Sci. 2018, 9, 1634.

[59] Jiang, Z.; Zhang, Y.; Ye, W.; Tan, C.-H. Tetrahedron Lett. 2007, 48, 51.

[60] Balint, E.; Takacs, J.; Drahos, L.; Keglevich, G. Heteroat. Chem. 2012, 23, 235

[61] Molleti, N.; Bjornberg, C.; Kong, J.-Y. Org. Biomol. Chem. 2016 $14,10695$.

[62] (a) Bourderioux, A.; Routier, S.; Beneteau, V.; Merour, J.-Y. Tetrahedron 2007, 63, 9465 .

(b) Bouissane, L.; Sestelo, J.-P.; Sarandeses, L. A. Org. Lett. 2009 11,1285 .

(c) Awuah, E.; Capretta, A. J. Org. Chem. 2011, 76, 3122.

(d) Souffrin, A.; Croix, C.; Viaud-Massuard, M.-C. Eur. J. Org Chem. 2012, 13, 2499

[63] Roshchin, A.-I.; Polunin, E.-V. Mendeleev Commun. 2008, 18, 332.

[64] Lim, L.-H.; Zhou, J. Org. Chem. Front. 2015, 2, 775.

[65] Jafarpour, F.; Shamsianpour, M.; Issazadeh, S.; Dorrani, M.; Hazrati, H. Tetrahedron 2017, 73, 1668.

[66] Jafarpour, F.; Shamsianpour, M. RSC Adv. 2016, 6, 103567.

[67] Yang, Z.-H.; An, Y.-L.; Chen, Y.; Shao, Z.-Y.; Zhao, S.-Y. Adv. Synth. Catal. 2016, 358, 3869.

[68] Dana, S.; Mandal, A.; Sahoo, H.; Baidya, M. Org. Lett. 2017, 19, 1902.

[69] An, Y.-L.; Zhang, H.-H.; Yang, Z.-H.; Lin, L.; Zhao, S.-Y. Eur. J. Org. Chem. 2016, 2016, 5405.

[70] Kong, D.-H.; An, Y.-L.; Shao, Z.-Y.; Zhao, S.-Y. J. Chem. Res. 2018, 42, 476 .

[71] (a) Yang, Z.-H.; Tan, H.-R.; An, Y.-L.; Zhao, Y.-W.; Lin, H.-P.; Zhao, S.-Y. Adv. Synth. Catal. 2018, 360, 173.

(b) Yang, Z.-H.; Zhu, J.-N.; Jin, Z.-H.; Zheng, J.; Zhao, S.-Y. Synthesis 2018, 50, 4627.

[72] Yang, Z.-H.; Tan, H.-R.; Zhu, J.-N.; Zheng, J.; Zhao, S.-Y. Adv. Synth. Catal. 2018, 360, 1523. 
[73] (a) Maruoka, H.; Okabe, F.; Koutake, Y.; Fujioka, T.; Yamagata, K. Heterocycles 2009, 77, 617.

(b) Bai, J.-F.; Guo, Y.-L.; Peng, L.; Jia, L.-N.; Xu, X.-Y.; Wang, L.-X. Tetrahedron 2013, 69, 1229.

(b) Petrelli, A.; Samain, E.; Pradeau, S.; Halila, S.; Fort, S. ChemBioChem 2017, 18, 206.

[74] Baker, J.-R.; Tedaldi, L.-M.; Aliev, A.-E. Chem. Commun. 2012, 48, 4725 .

[75] Lin, C.; Zhen, L.; Cheng, Y.; Du, H.-J.; Zhao, H.; Wen, X.; Kong, L.-Y.; Xu, Q.-L.; Sun, H. Org. Lett. 2015, 17, 2684.

[76] Ding, G.; Wu, X.; Jiang, L.; Zhang, Z.; Xie, X. Org. Lett. 2017, 19, 6048.

[77] Qiu, S.; Lee, R.; Zhu, B.; Coote, M.-L.; Zhao, X.; Jiang, Z. J. Org. Chem. 2016, 81, 8061 .

[78] Nishikawa, Y.; Nakano, S.; Tahira, Y.; Terazawa, K.; Yamazaki, K.;
Kitamura, C.; Hara, O. Org. Lett. 2016, 18, 2004.

[79] Kumar, G.-V.; Govindaraju, M.; Renuka, N.; Khatoon, B.-B.-A.; Mylarappa, B.-N.; Kumar, K.-A. Rasayan J. Chem. 2012, 5, 338.

[80] Liu, G.-N.; Luo, R.-H.; Zhou, Y.; Zhang, X.-J.; Li, J.; Yang, L.-M.; Zheng, Y.-T.; Liu, H. Molecules 2016, 21, 1198/1.

[81] Zhang, X.-N.; Chen, G.-Q.; Tang, X.-Y.; Wei, Y.; Shi, M. Angew. Chem., Int. Ed. 2014, 53, 10768 .

[82] Sharma, S.; Han, S. H.; Oh, Y.; Mishra, N.-K.; Lee, S.-H.; Oh, J.-S.; Kim, I.-S. Org. Lett. 2016, 18, 2568.

[83] Morita, T.; Akita, M.; Satoh, T.; Kakiuchi, F.; Miura, M. Org. Lett. 2016, $18,4598$.

[84] Yu, W.; Zhang, W.; Liu, Y.; Liu, Z.; Zhang, Y. Org. Chem. Front. 2017, 4, 77 .

[85] Zhu, C.; Falck, J.-R. Chem. Commun. 2012, 48, 1674.

[86] Miura, W.; Hirano, K.; Miura, M. Org. Lett. 2015, 17, 4034.

(Cheng, F.) 